\title{
The effect of carbon nanotube amount in machining of ZA-27 matrix carbon nanotube reinforced nano composite
}

Muharrem Pul ( $\nabla$ mpul@kku.edu.tr)

Kırıkkale Üniversitesi: Kirikkale Universitesi

\section{Research Article}

Keywords: Nano composite, Carbon nanotube, ZA-27, Machinability

Posted Date: April 1st, 2021

DOl: https://doi.org/10.21203/rs.3.rs-355460/v1

License: (1) (1) This work is licensed under a Creative Commons Attribution 4.0 International License.

Read Full License 


\title{
The effect of carbon nanotube amount in machining of ZA-27 matrix carbon nanotube reinforced nano composite
}

\author{
Muharrem Pul \\ Department of Electric and Energy, Kırıkale University, Kırıkkale 71450, Turkey \\ mpul@kku.edu.tr
}

\begin{abstract}
In this study, the effect of carbon nanotube (CNT) on the machining of CNT-reinforced ZA-27 (zinc-aluminum alloy) nano composite was investigated. For this purpose, 0.5\%, 1.0\%, 1.5\%, 3.0\% CNT-reinforced ZA-27 based composites were produced by powder metallurgy method. Firstly, microscope images of the composites were taken, and hardness and density measurements were made. Then machining tests were carried out. Machinability tests were carried out by turning method to determine the cutting forces and surface roughness values. The tests were carried out with cemented carbide cutting tools under dry cutting conditions. Cutting speeds of 75, 125 , $175,225 \mathrm{~m} / \mathrm{min}$, feed values of $0.05,0.10,0.20 \mathrm{~mm} / \mathrm{rev}$ and constant cutting depth of $1.0 \mathrm{~mm}$ were chosen as test parameters. The data obtained as a result of the tests were interpreted together with microstructure, porosity and hardness values. Hardness values decreased and the pore amounts increased with the increase in the CNTreinforcement ratio within the composite structure.Cutting forces and the surface roughness amounts increased with the increase in feed value. Cutting forces and surface roughness values decreased together with increase in cutting speed. CNT-reinforcement material in the composite structure caused a decrease in cutting forces. However, surface roughness values showed an increase with the increase of CNT-reinforcement ratio. It has been determined that CNT-reinforcement material facilitates machining by lubricating effect in dry machining conditions. Built-up edge (BUE) was observed on all cutting tool bits used in machining tests. BUE amounts increased in itself with the increase in CNT ratios and feed rates.
\end{abstract}

Keywords: Nano composite; Carbon nanotube; ZA-27; Machinability

\section{Introduction}

The use of composite materials has been increasing rapidly in many industries. One type of these composite materials are metal matrix composite (MMCs) materials. Most of the researches about MMCs are on light metal alloys such as aluminum and magnesium. However, in recent years, studies on metallic composites using zinc and zinc alloys have started. Zinc-based alloys are very useful as a matrix material due to their low melting temperatures and being cheap. Zinc-aluminum alloys are preferred matrix materials due to their high strength/density ratio and superior tribological properties. ZA-27 alloy is very popular among zinc-based alloys used as matrix material [1]. Due to its suitability for mass production, high corrosion resistance, low melting temperature and superior workability, ZA-27 zinc-aluminum alloy is widely used in fields such as automotive and construction industry, sports equipment, toys, hardware, decoration, and white goods. Another name for the ZA-27 alloy is ZAMAK. Different reinforcement materials are added to the ZA-27 alloy and efforts are made to improve its mechanical and tribological properties. In the development of the properties of composite materials, the reinforcing element is as effective as the main material. The reinforcing element carries a large part of the load on the composite. In the production of such MMCs materials, micron size ceramic based reinforcement materials such as $\mathrm{B}_{4} \mathrm{C}, \mathrm{SiC}, \mathrm{SiO}_{2}, \mathrm{Al}_{2} \mathrm{O}_{3}, \mathrm{MgO}, \mathrm{TiB}_{2}$ and $\mathrm{TiC}$ are mostly used. However, in recent years, carbon nanotube and nano graphene added composite materials have become more popular due to their superior physical and mechanical properties such as high modulus of elasticity, high strength and abrasion resistance. Nano material reinforced composites have superior properties compared to micron sized particle reinforced composites.

Carbon nanotubes (CNT) started to be investigated intensively after their discovery in the early 1990s, after their extraordinary properties were noticed. In many practical and theoretical studies, carbon nanotubes have become a "model system" for nanotechnology. CNTs are perhaps the most important of all other 1D nano materials. $\mathrm{CNT}$, in the simplest sense, is nm (nanometer) diameter, $\mu \mathrm{m}$ (micron) tall tubular structures. In other words, CNTs are in the form of a hollow cylinder, made of single or more graphene (a single layer of graphite) sheet, when viewed structurally (Fig. 1). The diameter of the cylinder in question can range from $0.4 \mathrm{~nm}$ to $100 \mathrm{~nm}$ or higher. However, he proposed classifying tubular structures with diameters above $15 \mathrm{~nm}$ as "carbon nanofibers". Depending on the production method and conditions, the lengths of CNTs can range from hundreds of $\mu \mathrm{m}$ to $\mathrm{cm}$ 
[2]. Research in the field of carbon revolutionized 1991 with the discovery of carbon nanotubes by Iijima. Experiments and simulations have shown that CNTs have outstanding mechanical properties compared to carbon fibers. CNT can reach hardness of $1000 \mathrm{GPa}$, resistance of $100 \mathrm{GPa}$ and thermal conductivity up to $6000 \mathrm{~W} \mathrm{m-1}$ $\mathrm{K}-1$. These studies show that CNTs are the strongest fibers with extraordinary properties known to mankind [3]. Carbon nanotubes are produced in two ways, single-walled and multi-walled. In Fig. 1, a schematic view of the formation of graphene nano plate and carbon nano tubes is given.

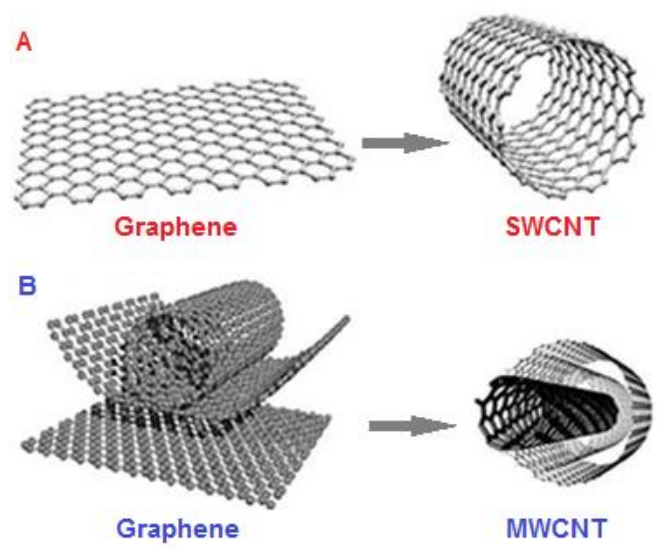

Fig. 1 Graphene and carbon nanotubes as (A) single wall carbon nanotube (SWCNT) and (B) multi-wall carbon nanotube (MWCNT) structures [4]

Today, the usage area of nano material reinforced composites, which provides more economical, lighter and improved mechanical properties, is rapidly increasing. With this increase, the machining of nano-reinforced composites according to the usage area also comes to the agenda. Their behaviors against machining (manufacturing) gained importance in evaluating the commercial usability of the composite materials produced. The performance of the cutting tools used in the machining of these materials directly affects both the quality of the processed material and the production costs. The cutting forces generated in the cutting tool during machining are the most important parameters in terms of determining the economics and power needs of the process. Interactions between cutting forces and cutting tool are of great importance in terms of cutting tool wear or breakage. Measuring cutting forces is essential for optimizing tool design as well as for scientific analysis [5]. Measuring the forces affecting the cutting tool with sufficient precision is done with a dynamometer. Cutting forces can be measured by using the dynamometers on the principle of measuring the elastic deformation of the cutting tool under load. Fig. 2 shows the cutting force components that occur during the turning process.

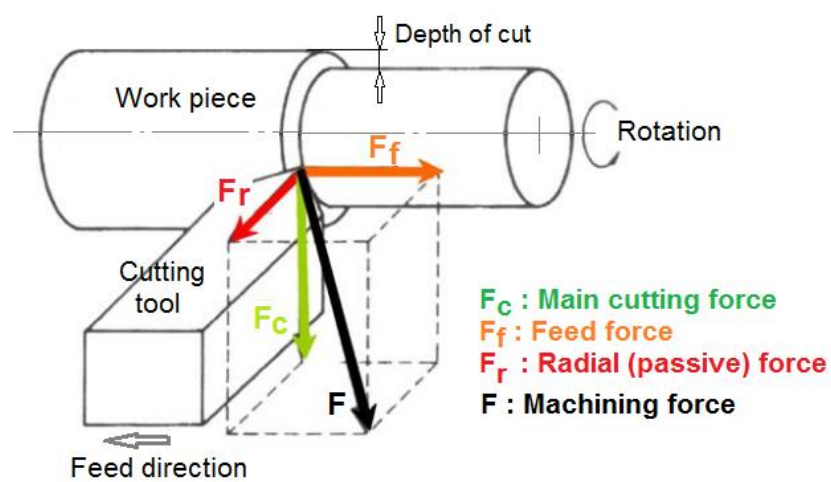

Fig. 2 Cutting force components in turning [6]

Where, $F_{C}$ is the actual cutting force and acts perpendicular to the cutting tool tip on the tool-chip surface. $F_{C}$ is usually the largest of the three force components. $F f$ is the feed force and acts on the cutting tool parallel to the workpiece axis. $F r$ is radial (passive) force and tries to move the cutting tool away from the workpiece. $F r$ acts on the cutting tool axis and is usually the smallest force component. The resultant force $F$ is the sum of these three force components in vector and is calculated with the help of Eq. 1.

$$
F=\sqrt{F c^{2}+F f^{2}+F r^{2}}
$$


Of these three force components, $F c$ main cutting force is the most important. The $F c$ main cutting force determines the size of the torque that must be transmitted by the machine tool's main shaft and the power consumption during the cutting process [7]. According to the literature, the main cutting force value is the product of the specific cutting resistance of the material processed with the chip cross section (Eq. 2).

$$
F c=A . k s
$$

Where $A\left(\mathrm{~mm}^{2}\right)$ is the area of the chip cross section, $k s\left(\mathrm{~N} / \mathrm{mm}^{2}\right)$ is the specific cutting resistance of the material. According to experimental studies, there are other parameters that affect the main cutting force. These factors are chip angle factor $\mathrm{k} \gamma$, cutting speed factor $\mathrm{kv}$, tool wear factor ka and tool material factor kt. In this case, the main cutting force is calculated according to Eq. 3 .

$$
F c=A \cdot k s \cdot k v \cdot k \gamma \cdot k a \cdot k t
$$

The required machine power can be calculated by multiplying the $F c$ main cutting force and cutting speed (Eq. 4).

$$
P=V \cdot F c
$$

Where $V(\mathrm{~m} / \mathrm{min})$ is the cutting speed, $\mathrm{P}(\mathrm{Nm} / \mathrm{min}$ or Watt) is the machine power. Powder metallurgy method is generally preferred in the production of parts that do not require machining after production. However, in some cases, metal removal processes are carried out on the parts produced by powder metallurgy. Therefore, studies on the machining of parts produced by powder metallurgy are not included in the literature. In this experimental study, the cutting forces formed in turning of CNT-reinforced ZA-27 matrix composites produced by powder metallurgy method were measured. At the same time, the roughness of the machined surfaces was measured and recorded. Data obtained at the end of measurements and tets were evaluated together.

\section{Materials and methods}

In this experimental study, powder ZA-27 zinc-aluminum alloy with 37-63 $\mu \mathrm{m}$ grain size was used as matrix material and carbon nanotube (CNT) was used as a reinforcing element. Technical properties of the test materials are given in Table 1.

$\underline{\text { Table } 1 \text { Technical properties of CNT and ZA-27 }}$

\begin{tabular}{lc|lc}
\hline \multicolumn{1}{c|}{ CNT } & \multicolumn{2}{c}{ ZA-27 } \\
\hline Parameters & Values & Parameters & Values \\
\hline Purity $(\%)$ & 92 & $\mathrm{Al} \%$ & $25.5-28.0$ \\
Outer diameter $(\mathrm{nm})$ & $8-10$ & $\mathrm{Mg} \%$ & $0.01-0.02$ \\
Inner diameter $(\mathrm{nm})$ & $5-8$ & $\mathrm{Cu} \%$ & $2.0-2.5$ \\
Length $(\mu \mathrm{m})$ & $1-3$ & $\mathrm{Fe} \%$ & 0.075 \\
Color & Black & $\mathrm{Zn} \%$ & Remaining \\
Electrical conductivity $(\mathrm{S} / \mathrm{m})$ & 9800 & Density $\left(\mathrm{g} / \mathrm{cm}^{3}\right)$ & 5.0 \\
Heat conductivity $(\mathrm{W} / \mathrm{mK})$ & $3.0 \times 103$ & Melting point $\left({ }^{\circ} \mathrm{C}\right)$ & $376-484$ \\
Spesific Suurface Area $\left(\mathrm{m}^{2} / \mathrm{g}\right)$ & 240 & Hardness $($ Brinell) & $105-125$ \\
Density $\left(\mathrm{g} / \mathrm{cm}^{3}\right)$ & 2.6 & Tensile strength $(\mathrm{Mpa})$ & 421 \\
& & Thermal conductivity $(\mathrm{W} / \mathrm{mK})$ & 123 \\
& & Electrical conductivity $(\mathrm{S} / \mathrm{m})$ & 1,72 \\
\hline
\end{tabular}

In the production of nano-reinforced composite materials, $0.5 \%, 1.0 \%, 1.5 \%$ and $3.0 \%$ weight ratio of CNTreinforcement was determined. A homogeneous mixture was obtained by mixing ZA-27 and CNT nano materials at the calculated weight ratios in the ball mill for $120 \mathrm{~min}$ at $300 \mathrm{rpm}$. During the mixing process, $5 \mathrm{~mm}$ diameter $\mathrm{ZrO} 2$ based balls were used. The material / ball weight ratio in the mixing was chosen as $5 / 1$. In order to increase the slippage and reduce friction so that the composite samples can eanay get out of the mold after the compression process, $0.5 \%$ lubricant has been added to the composite powder mixture. After mixing, ZA27+CNT composite mixtures were compressed into the press under $500 \mathrm{MPa}$ pressure in a $30 \mathrm{~mm}$ diameter mold. Before the compressing process, the composite mixtures and mold were preheated at 300 degrees. In the hardness measurements, $15.625 \mathrm{~kg}$ load was applied and a measuring ball of $2.5 \mathrm{~mm}$ diameter was used. Composite samples whose compression process has been completed were subjected to sintering at a temperature of $450^{\circ} \mathrm{C}$ for $120 \mathrm{~min}$ in a heat treatment furnace. After the sintering process, the production process of nano composite materials has been completed. Then, in order to examine the microstructures of composite materials, images were taken with scanning electron microscopy (SEM). The porosity and hardness value of the composite 
structure are important parameters affecting the machinability. For this purpose, the density values of the composite samples were determined according to the Archimedes principle. According to the density values obtained, the porosity amounts of the composites were calculated in $\%$. Then the hardness measurements of composite materials were made according to the Brinell method. In the hardness measurements, $15.625 \mathrm{~kg}$ load was applied and a measuring ball of $2.5 \mathrm{~mm}$ diameter was used. After the density and hardness measurements, machinability tests were started. The composite samples produced were fixed to the CNC lathe using an apparatus. Machining tests were carried out using SNMG 120408 LT10 coded cutting tools shown in Fig. 3. The machining test parameters were selected within the value ranges recommended by the cutting tool manufacturer. As test parameters, cutting speeds of 75, 125, 175 and $225 \mathrm{~m} / \mathrm{min}, 0.05-0.10-0.20 \mathrm{~mm} / \mathrm{rev}$ feed and $1.0 \mathrm{~mm}$ constant cutting depth were chosen.

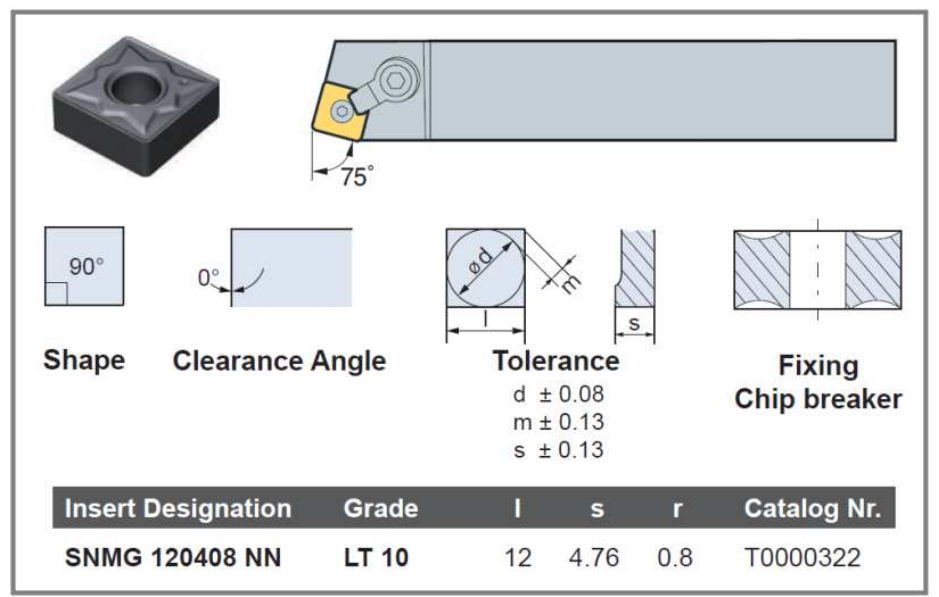

Fig. 3 Cutting tool and tool holder used in machining tests

Cutting forces were recorded with a dynamometer during machining tests. At the same time, the roughness value of each machined surface was measured. In roughness measurements, arithmetic means of the values measured from five different regions of the surface are taken into account. The machining tests setup is shown schematically in Fig. 4.

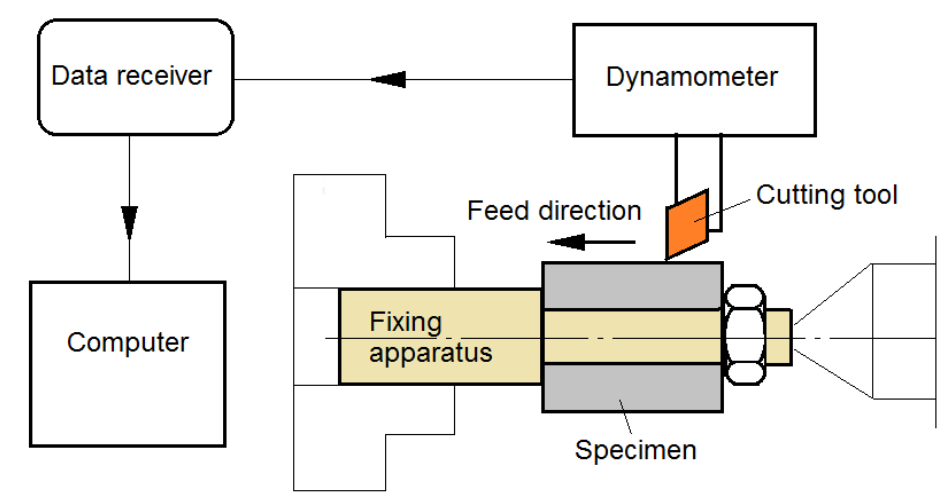

Fig. 4 Machining test setup

\section{Findings and Discussion}

\subsection{Evaluation of microstructures}

Topographic SEM images of $0.5 \%, 1.0 \%, 1.5 \%$ and $3.0 \%$ CNT-reinforced ZA-27 matrix nano composite samples produced by powder metallurgy method are given in Fig. 5. 

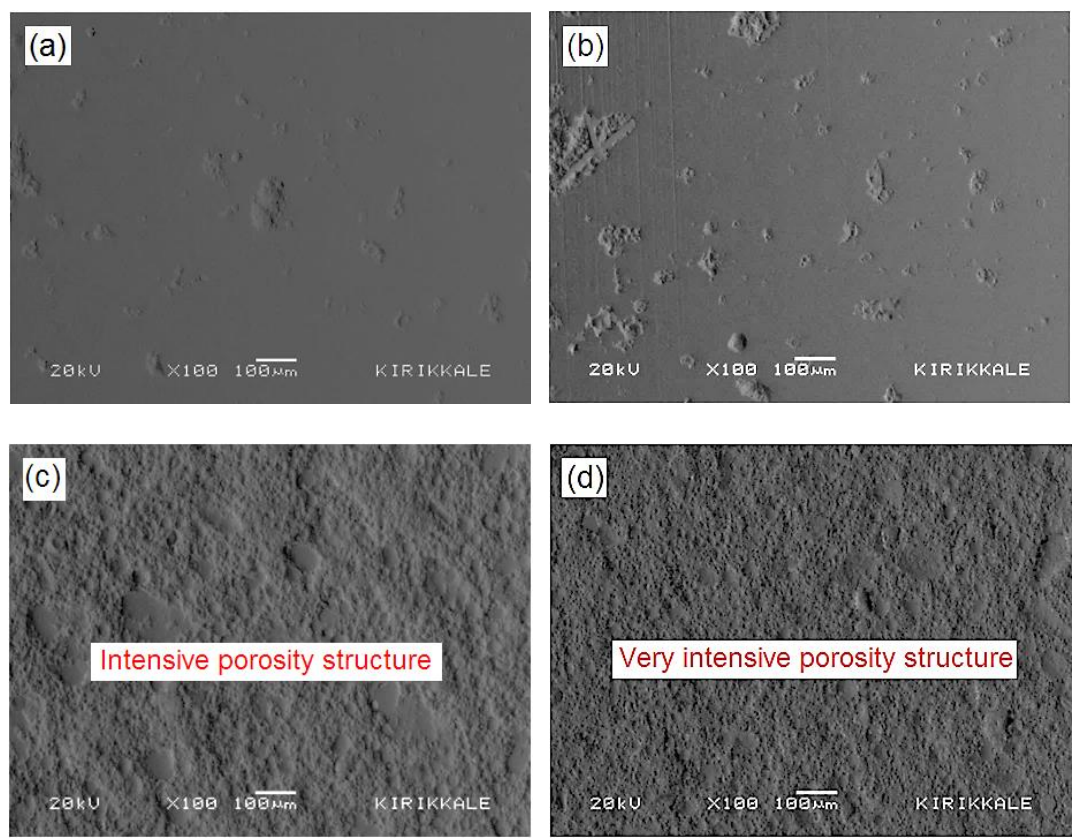

Fig. 5 Microstructures of $0.5 \%$ CNT (a), 1.0\% CNT (b), 1.5\% CNT (c), 3.0\% CNT (d) reinforced ZA-27 matrix nano composites

Looking at the SEM images in Fig. 5, it is remarkable that the microstructure undergoes a sudden change with the CNT-reinforcement ratio exceeding $1.0 \%$. Although the same surface preparation process is applied to all composite samples, the extremely irregular and rough structure on the surfaces of $1.5 \%$ and $3.0 \%$ CNT doped composites is noteworthy. It is understood that the binding between ZA-27 particles weakened and deteriorated with the amount of CNT exceeding $1.0 \%$. A tendency to aggregate emerged among the ZA-27 particles that could not be interconnected by sintering. It is understood that the porous areas in the composite structure increased at a very high rate with the CNT-reinforcement ratio exceeding $1.0 \%$. CNT nano materials are considered to be intensely located between the particles of ZA-27 matrix material in places. As a result, it is understood that ZA-27 particles cannot be sintered at the desired level and the formation of neck and ligament between the grains is weak. The very high specific surface area values (CNT $\left.=240 \mathrm{~m}^{2} / \mathrm{g}\right)$ and the surface energy of the CNT-reinforcing material are considered to be effective during sintering and may reduce heat transfer by forming an interface between ZA-27 particles. In order to see the nano materials in the composite structure more detailed, SEM images taken from the composite sample with a $3.0 \%$ reinforcement ratio at $20,000 \times$ magnification are given in Fig. 6.
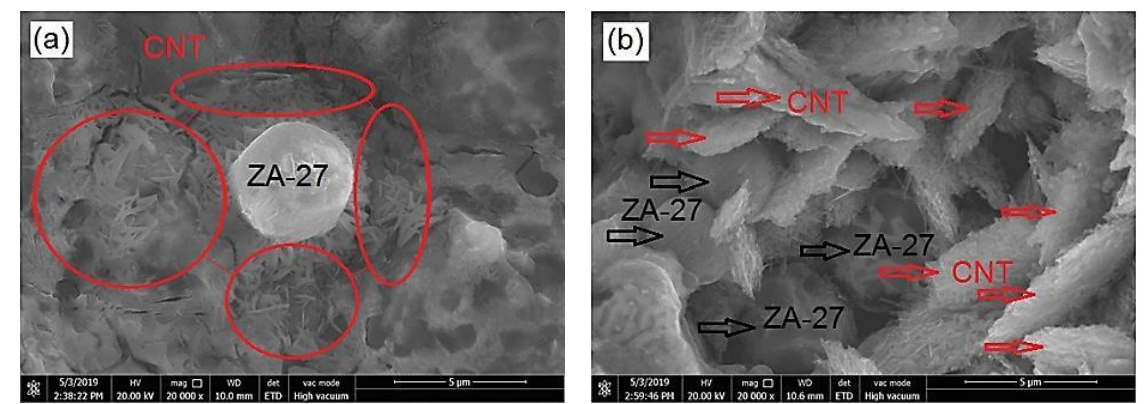

Fig. 6 CNT-reinforcing elements in composite structure

When the SEM images in Fig. 6 are examined, CNT nano materials can be selected eanay in the composite structures. Especially when the SEM image in Fig. 6 (a) is carefully examined, it appears that the CNTreinforcement material completely encloses the ZA-27 particle. In the SEM image of Fig. 6 b, it is understood that the CNT nano materials are agglomerated and placed between the ZA-27 matrix material particles. It also appears that ZA-27 particles cannot form bonds during sintering. As said earlier, CNT particles on ZA-27 particles that cover part of the particle surface are considered to cause weakening of heat conduction. In this case, it can be stated that the effect of sintering temperature decreases between ZA-27 grains, and inter-grain bonding is negatively affected. 


\subsection{Evaluation of hardness and porosity quantity}

The graphs of ZA-27 matrix and CNT-reinforced nano composite samples, which are determined by the hardness and Archimedes principle determined according to the Brinell method, are given in Fig. 7.
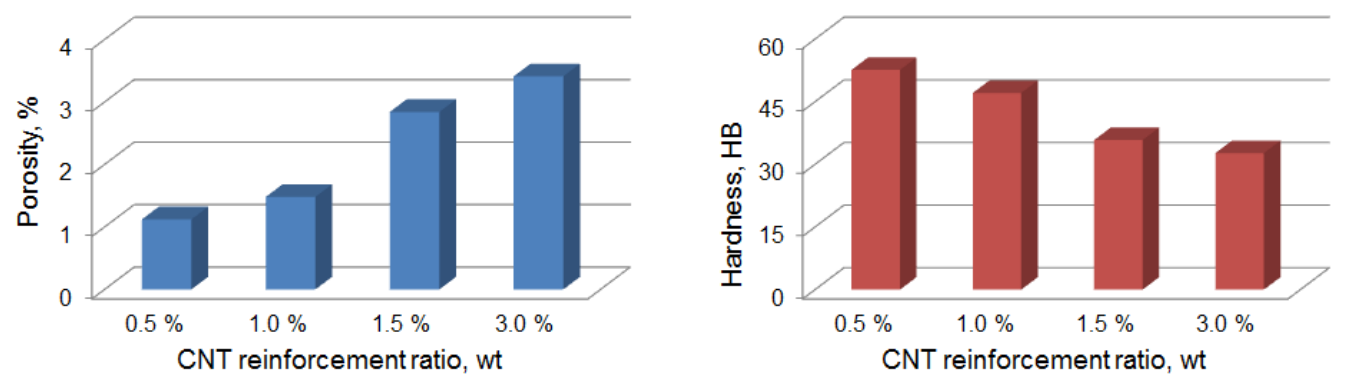

Fig. 7 Hardness and porosity amounts of Nano CNT-reinforced ZA-27 composites.

Looking at the graphs in Fig. 7, it appears that the porosity rates are increasing due to the increase in the nano CNT-reinforcement rate. Similar results were reported in different studies [8-11]. The fact that the CNTreinforcing element is nano-sized made it difficult to homogeneously distribute the reinforcement into the ZA-27 matrix during mixing. This situation has become more difficult with increasing CNT-reinforcement rates and it has been evaluated to increase the porosity amounts in the composite structure. Similar results were included in the literature [10,12]. Close porosity amounts occurred at $0.5 \%$ and $1.0 \%$ CNT-reinforcement rates. However, with the CNT supplement rate rising to $1.5 \%$, a sudden increase in porosity ratio occurred. While $1.0 \% \mathrm{CNT}$ reinforced composite has $1.41 \%$ pore ratio, this ratio increased to $2.79 \%$ in $1.5 \%$ CNT-reinforced composite. The binding between ZA-27 particles was negatively affected by the increase in CNT rate to $1.5 \%$. CNT nanoparticles located between the ZA-27 matrix particles reduced the effect of sintering and led to the formation of pores between the ZA-27 particles. Looking at the SEM images in Fig. 7, it appears that the CNT-reinforcing elements are aggregated around the ZA-27 particles. As a result, it is considered that the porosity rates of $1.5 \%$ and 3.0\% CNT-reinforced composites increase. In addition, when looking at the microstructure images in Fig. 5 (c) and (d), the relationship between reinforcemenet ratio and porosity can be clearly observed.

When the hardness graph in Fig. 7 is analyzed, it is seen that the hardness values decreased significantly with the increase of the CNT-reinforcement ratio. There are studies in the literature that show similar results [12-13]. It is known that pure pure 100\% ZA-27 alloy has theoretical hardness values between 53-56 HB. However, the lowest hardness value measured in composite samples was measured with $32.8 \mathrm{HB}$ and $3.0 \%$ CNT doped sample. The highest hardness value was measured in $51.5 \mathrm{HB}$ and $0.5 \% \mathrm{CNT}$-reinforced sample. The CNT nano material additive reduced the hardness of the composite structure at a very high rate. In particular, CNT supplements at rates higher than $1.0 \%$ (1.5\% to 3.0\%) appear to have a much greater effect on hardness values. It is understood that there is a direct relationship between the hardness values and porosity rates of nano composite materials. The highest hardness value was obtained in $0.5 \%$

CNT-reinforced sample with the lowest porosity rate. With the increase of porosity in the composite structure, there was a serious decrease in hardness values. Thus, with the CNT-reinforcement ratio rising to $3.0 \%$, compared to the non-reinforced ZA-27 material, the hardness value decreased almost by half. As can be seen from the microstructure images in Fig. 5, the bond formation of ZA-27 particles during sintering has been significantly reduced with the contribution of nano material $1.5 \%$ and above. It is evaluated that all of the temperature occurring during sintering does not affect the matrix material and some of it is absorbed by CNTreinforcing elements. It is believed that the fact that CNT nano materials have a very high specific surface area causes this situation. Thus, the pores formed between the ZA-27 particles that cannot be bonded together decreased the hardness value of the composite structure while increasing the porosity ratio.

\subsection{Evaluation of cutting forces}

In Fig. 8, graphs drawn according to the cutting force values obtained from the machining experiments of $0 \%$, $0.5 \%, 1.0 \%, 1.5 \%$ and 3.0\% CNT-reinforced ZA-27 composite samples are given collectively. The graphs show the changes in the actual cutting force Fc, feed force Ff, and radial force Fr, depending on the feed rates and cutting speeds. 

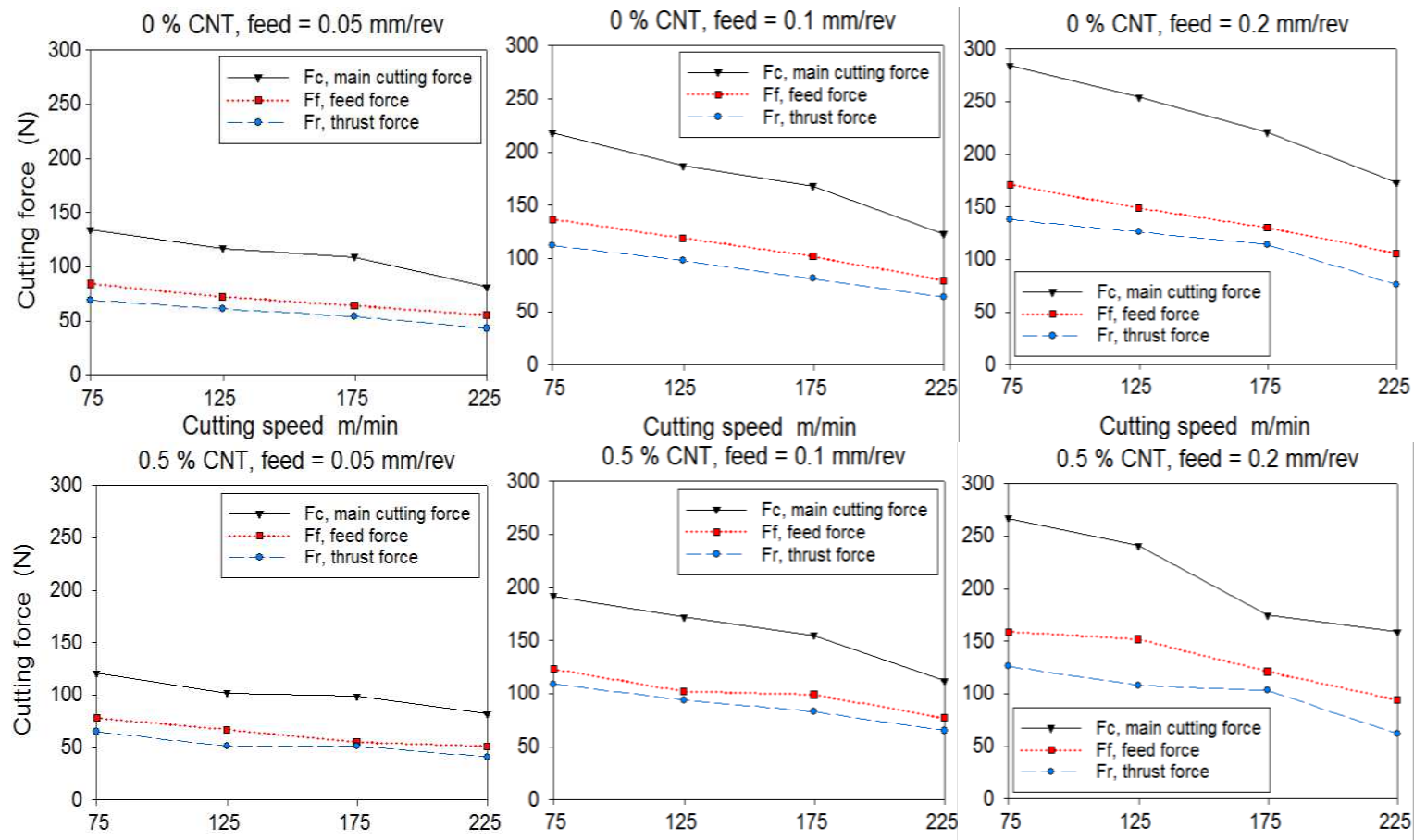

Cutting speed $\mathrm{m} / \mathrm{min}$

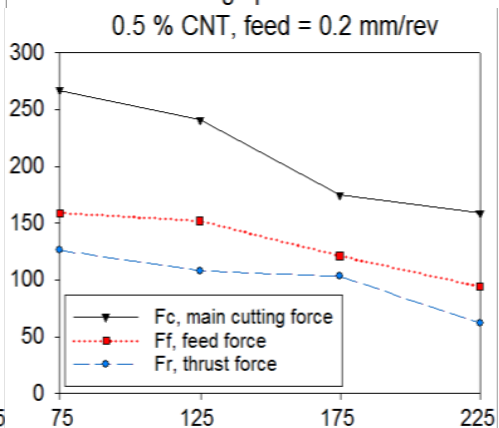

Cutting speed $\mathrm{m} / \mathrm{min}$

Cutting speed $\mathrm{m} / \mathrm{min}$

Cutting speed $\mathrm{m} / \mathrm{min}$
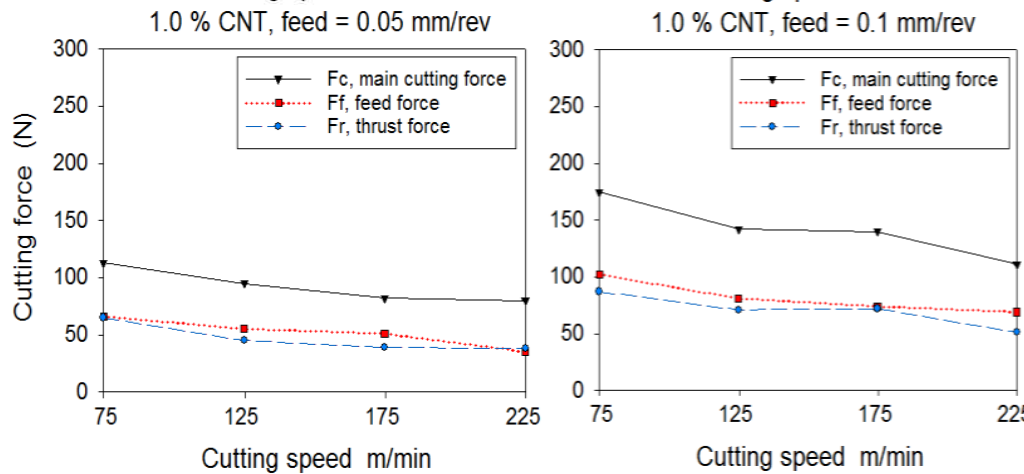

Cutting speed $\mathrm{m} / \mathrm{min}$

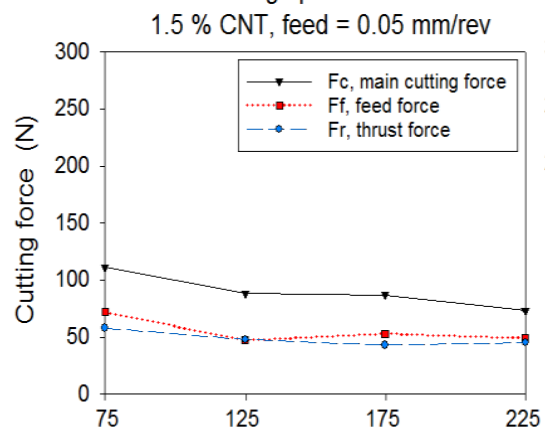

$1.5 \%$ CNT, feed $=0.1 \mathrm{~mm} / \mathrm{rev}$
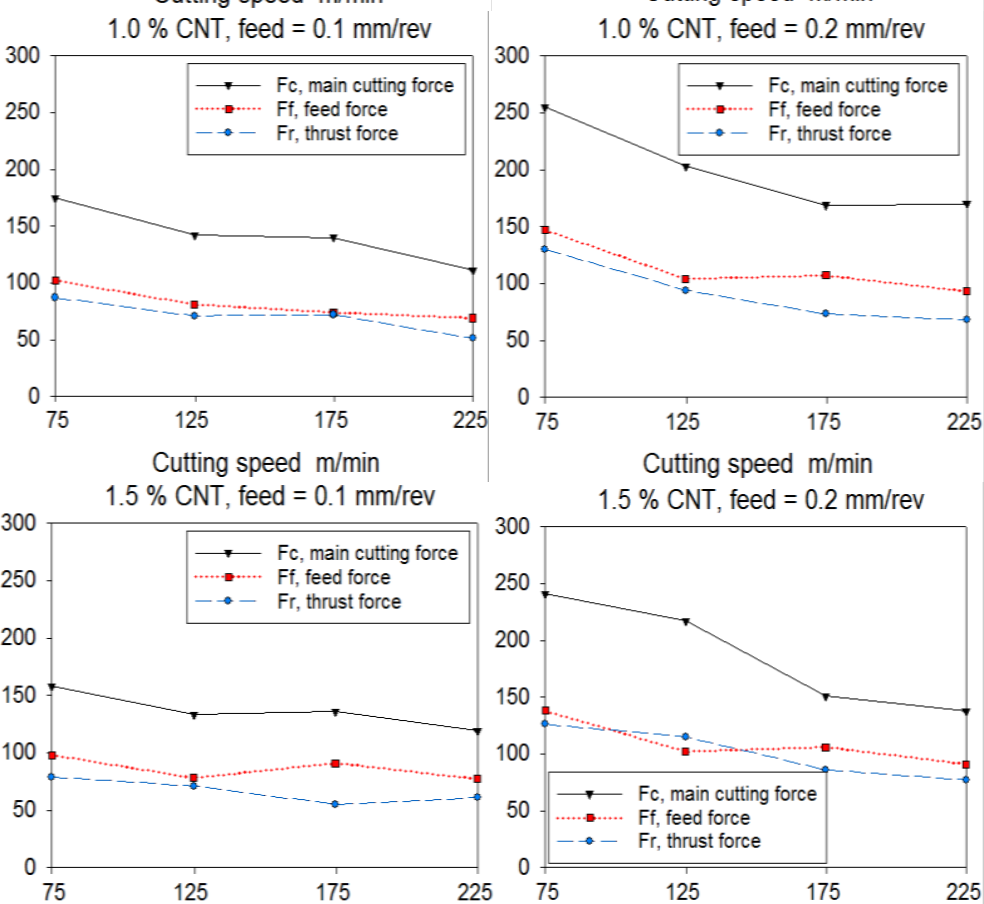

Cutting speed $\mathrm{m} / \mathrm{min}$

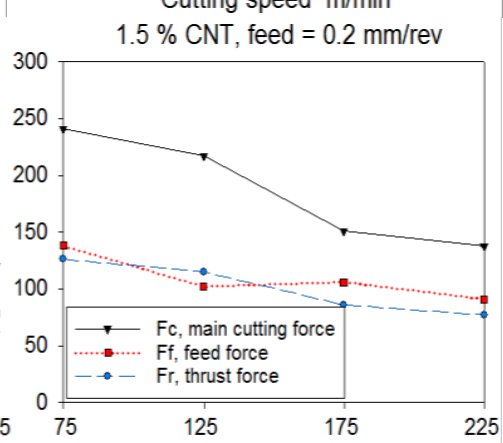

Cutting speed $\mathrm{m} / \mathrm{min}$

Cutting speed $\mathrm{m} / \mathrm{min}$

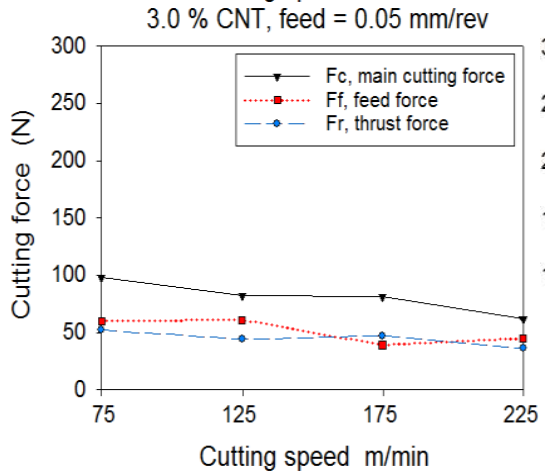

$3.0 \%$ CNT, feed $=0.1 \mathrm{~mm} / \mathrm{rev}$

Cutting speed $\mathrm{m} / \mathrm{min}$
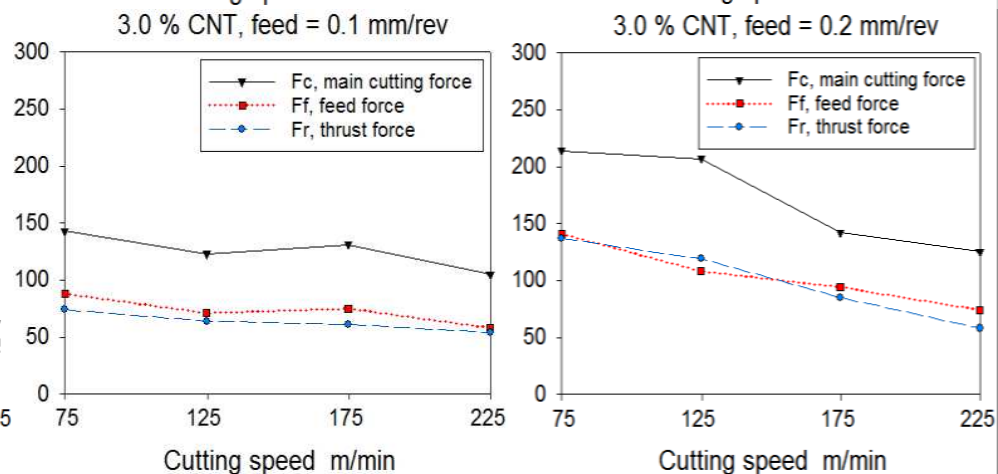

Fig. 8 Cutting forces measured in CNT/ZA-27 composites depending on feed and cutting speed. 
When looking at the graphs in Fig. 8 in bulk, it can be seen that cutting forces decrease with increasing speed. However, the increase in the amount of progress increased the cutting forces. It is possible to explain this situation depending on the increasing temperature in the cutting area with the increase in cutting speed. With the increase of temperature, with the effect of plastic deformation and thermal softening, friction in the tool-chip interface is reduced and chip flow is easier [14]. As a result, cutting forces tended to decrease. The lowest main cutting force was measured as $65 \mathrm{~N}$ in a $3 \%$ CNT-reinforced composite, at $0.05 \mathrm{~mm} / \mathrm{rev}$ feed rate, at a cutting speed of $225 \mathrm{~m} / \mathrm{min}$. The highest main cutting force was measured as $278 \mathrm{~N}$ in pure ZA-27 material without $\mathrm{CNT}$, at $0.2 \mathrm{~mm} / \mathrm{rev}$ feed rate, at a cutting speed of $75 \mathrm{~m} / \mathrm{min}$. Along with the increase in the amount of feed rate, the increasing tendency in the cutting forces is an expected situation due to the increase in the chip section. It is calculated from the "Chip section: Feed $\times$ Cutting depth" equation. According to this equation, cutting forces increase in direct proportion with the increase in the chip cross section area [15]. Looking at the graphs, it is clear that the most important parameter affecting the cutting force values are the changes in the feed ratevalue. Changes in cutting speed had less effect on cutting forces than changes in feed rates. When the graphs are analyzed, it is observed that there are some feed rate values and irregularities in the cutting forces of the cutting speeds. These irregularities in the cutting forces can be associated with CNT-reinforcing particles that are not evenly distributed in the composite structure. During the machining tests, the cutting tool can meet the regions where the tip of aggregated CNT particles or porous areas in the composite structure. In this case, there are instabilities in the forces acting on the cutting tool and sudden deviations occur in the measured cutting force values. Another reason for the irregularities in the cutting forces can be explained by the very low CNTreinforcement ratios and the cutting tool is generally in contact with the ZA-27 matrix. Due to its high ductility, ZA-27 zinc-aluminum alloy can form high built-up edge (BUE) at the cutting tool tip at low and medium cutting speeds. The formed BUE affects the cutting forces by increasing the friction or by suddenly breaking away from the tool tip. In a study in the literature, it is stated that BUE, which is formed in low reinforcement composites, is the main reason for the increase in cutting forces [14]. In such cases, a sharp cutting edge form, positively larger chip angle is recommended to avoid BUE and a ground tool surface is recommended to prevent sticking $[15,16]$. SEM images in Fig. 9 are given to examine the occurrence of BUE occurring in cutting tools in machining tests. For example, cutting tools used in the machining of $0 \%$ and 3.0\% CNT-reinforced nano composites were selected.

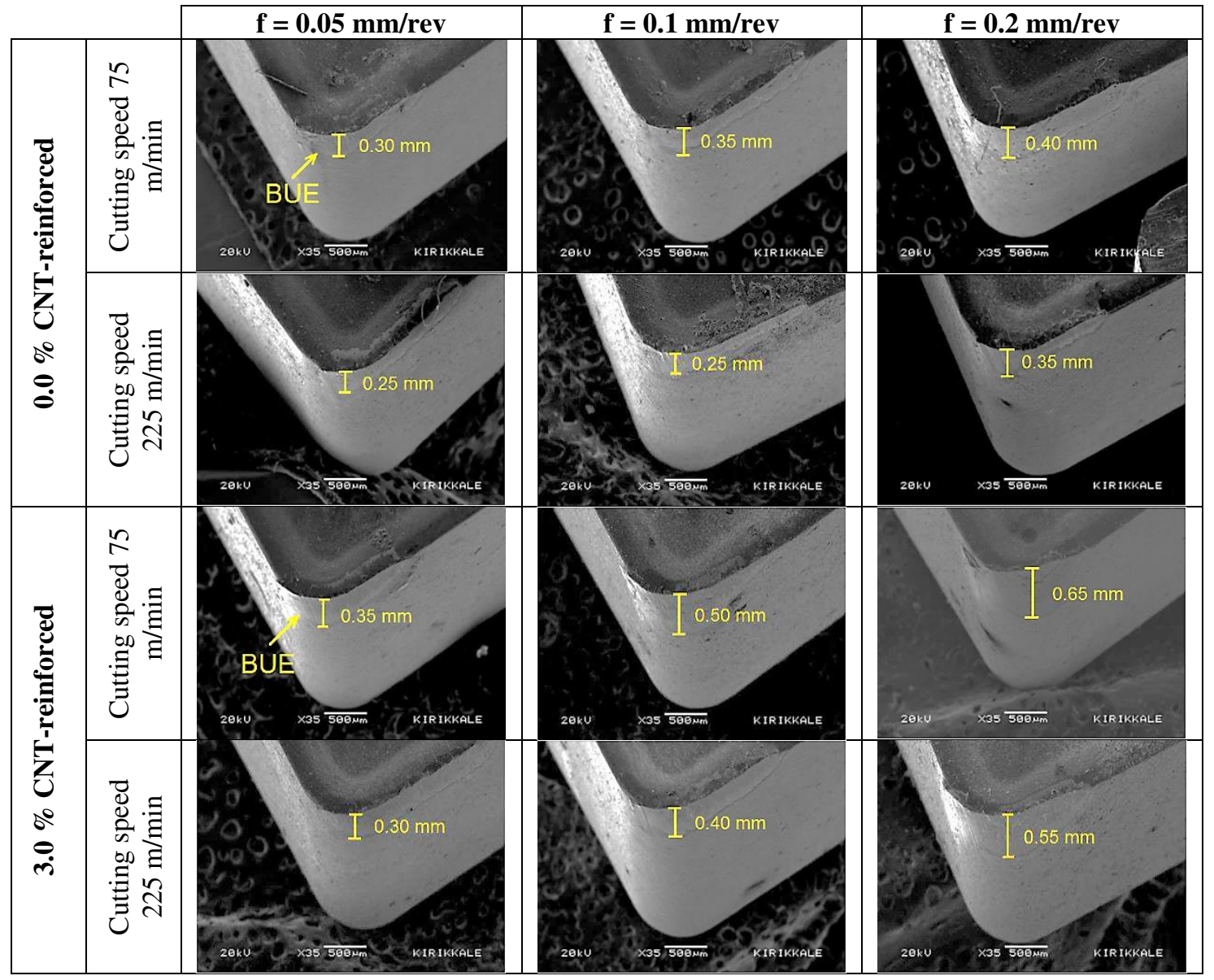

Fig. 9 Cutting tools used in $0 \%$ and 3\% CNT-reinforced composites machined at a cutting speed of $75 \mathrm{~m} / \mathrm{min}$, $225 \mathrm{~m} / \mathrm{min}$ and feed rate of $0.05 \mathrm{~mm} / \mathrm{rev}, 0.1 \mathrm{~mm} / \mathrm{rev}, 0.2 \mathrm{~mm} / \mathrm{rev}$ 
Looking at the SEM images in Fig. 9, it can be said that BUE occurs in all cutting tools. As stated earlier, some BUE is expected to occur in the machining of ZA-27 zinc-aluminum alloy, which is ductile. In addition, as in this study, BUE formation is seen more in machining experiments at low and medium cutting speeds. Another remarkable point in SEM images is that CNT-reinforcement material contributed to BUE formation. It is understood that the CNT-reinforcing material, which consists of graphite atoms, also exhibits some adhesion property at the same time as its lubricity. Therefore, in this experimental study, slightly more BUE than normal on tool surfaces has occurred. When the images in Fig. 9 are examined, it is understood that the amount of BUE increased with the increasing speed. In Figure 9, the approximate heights of the BUE occurring at the tool tip are given. According to the change in feed rates, the increase of BUE was more effective in tools where 3\% CNTreinforced materials were machined, compared to tools where 0\% CNT-reinforced pure ZA-27 material was machined. Increasing chip cross section with increasing feed rate naturally increases the amount of BUE. This is an expected situation and there are similar results in the literature [17-21]. The other point is that the amount of BUE formed at the tool tip has decreased slightly with increasing cutting speed. With the increase of cutting speed, it has become easier for the chip to move away from the tool tip. It can be said that chip adhesion to the tool surfaces is less with the increase in cutting speed. It can be stated that due to the effect of increasing temperature at high cutting speeds, it is easier for the chips to flow away from the tool surface. Looking at the images in Figure 9, it can be seen that the BUE heights in the machining tools at a cutting speed of $225 \mathrm{~m} / \mathrm{min}$ are slightly less than the machining at the cutting speed of $75 \mathrm{~m} / \mathrm{min}$.

Graphics in Fig. 8 continue to be examined, it is understood that the cutting forces decrease gradually with the increase of the CNT ratio in the composite structure. Although this downward trend was not very high, each feed and cutting speed continued to decrease steadily. Carbon nanotubes are the tubular form of nano-graphene plates. Graphene is a material with lubricant properties. Likewise, made of graphene plates, CNT has excellent lubricant properties [22]. Due to its CNT lubricant feature, it is evaluated that the tool tip facilitates the movement of the composite sample surface and helps with the chip removal process. In a study in literature, it is emphasized that reinforcing materials with lubrication properties such as graphite improve surface quality and machinability due to reduced friction [23]. Also, it is understood from the graphic in Fig. 2 that the hardness decreases with the increase of CNT rate. Hardness is one of the parameters directly affecting the cutting forces. Therefore, the decrease in cutting forces with the increasing CNT-reinforcement ratio has emerged as a natural result. Another issue is the effect of the porosity ratio of the composite structure on the cutting forces. With the increasing pore, some porous zones have formed in the composite structure. These porous zones caused a reduction in cutting forces and even irregularity. In the machining tests, when the cutting tool coincides with the porous regions, the forces acting on the tool tip decreased and reduced the cutting forces. Therefore, the increase of the CNTreinforcement ratio increased the pore ratio and caused the cutting forces to decrease. As a result, the lowest cutting forces were obtained from $3.0 \%$ CNT-reinforced composites

If the cutting forces are evaluated among themselves, it is seen that the main cutting force $F c$ is the highest cutting force. The second is the feed force $F f$ and the third is the radial cutting force $F r$. This sequence occurred in the same way in general for all machining experiments. Changes in the $F f$ and $F r$ cutting forces varied in proportion to the main cutting force $F c$. When looking at the graphs in Fig. 8, it is seen that the changes in $F f$ and $F r$ are proportional to $F c$. Cutting forces that occur during machining can vary depending on the type of machining, material type, cutting tool properties or machining parameters. However, there is an accepted approach in the literature on this subject. Where, in the approach, the $F f$ feed force and $F r$ radial force $F c$ are associated with the main cutting force. In general, $F f=(0.2 \sim 0.3) \times F c$ and $F r=(0.1 \sim 0.2) \times F c$ are considered as approximate values [16]. However, these approaches do not give an accurate result, they only help to estimate the cutting forces. In some publications, it is mentioned that the $F f$ feed force can be at higher values and the $F f$ feed force can reach up to $55 \%$ of the main cutting force [15, 24]. It is also stated in some studies that $\mathrm{Fr}$ radial force can rise up to half of the $F c$ main cutting force [25]. In addition, it is known that especially $F r$ radial force is highly affected by tool geometry, approach angle of tool, machining form and BUE formation. In some applications, it has been noted that $F r$ radial force rises up to the main cutting force values. In some cases, it has been stated that the nose radius of the tool increases and increases the radial force due to the BUE formed during the machining of ductile materials. In this case, the radial force $F r$ can be greater than the feed force $F f$ [24]. In a study in the literature, similar results were obtained with MMCs samples with SiC reinforced Al-Si matrix produced by powder metallurgy. While $F r$ is foreseen to be half of $F f$, it is stated that $F r$ is bigger than $F f$ [25].

Another factor affecting the cutting forces is the cutting tool nose radius. The relationship between cutting depth and tool nose radius applied in the experiments has more effect on the feed force $F f$ and radial force $F r$. In machining where the cutting depth is close to the tool nose radius, uncertainties can occur in the cutting forces. In such cases, $F f$ and $F r$ forces can be equal or very close to each other. This situation is shown schematically in Fig. 10. 
(a)

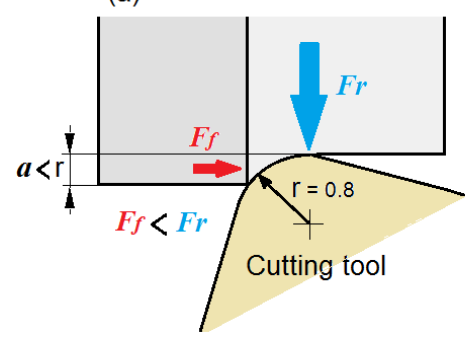

(b)

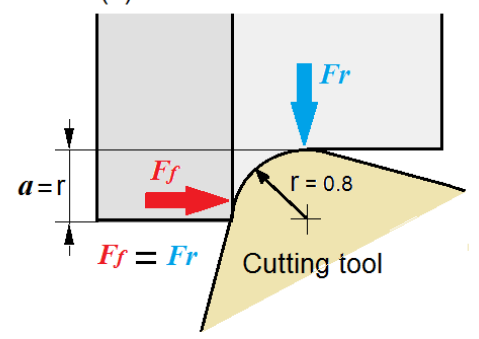

(c)

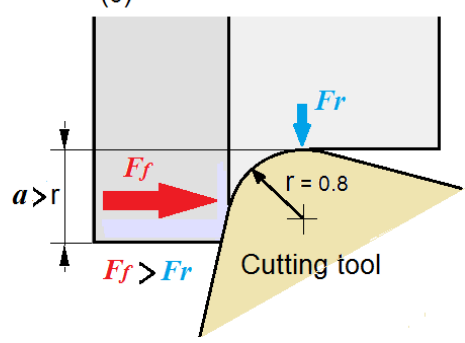

Fig. 10 Representation of the direction of the forces received by the tool when machining below and above the nose radius.

Fig. 10 shows the relationship between the depth of cut and the tool nose radius of the cutting tool in the occurrence of feed force $F f$ and radial force $F r$. If the cutting depth is larger than the tool nose radius, the feed force $F r$ may be greater than the radial force $F r$. Where the depth of cut is smaller than the nose radius, the radial force $F r$ will be greater than the feed force $F f$. This situation may vary slightly depending on the angle of approach of the cutting tool. After the cutting depth exceeds the tool nose nose radius (a>r), the thrust force $F f$ will retain the increase due to the increased chip removed. However, depending on the side cutting angle, some changes can be expected in the radial force Fr. The reason for these changes may be that the cutting tool is forced in the opposite direction during machining.

In this experimental study, $F r$ values were generally smaller than $F f$. However, at some points, $F f$ appeared at very close values, and at a few points, it was greater than $F f$. Looking at the graphs in Fig. 8, especially in $1.5 \%$ and 3.0\% CNT-reinforced composites, it is seen that radial force $F r$ is very close to feed force $F f$ or even more. BUE formed at the tool tip can cause Fr values to be higher than expected. It is often observed that the highly ductile structure of light metals such as ZA-27 forms BUE at the end of the cutting tool during machining. The resulting BUE is considered to increase the radial force $F r$ by increasing the tool nose radius. When the images in Fig. 9 are examined, it is seen that BUE accumulated on the tool tip enlarges the nose radius of the tool. In addition, porous regions in the composite structure are thought to affect the cutting forces to a small extent. It is evaluated that the cutting tool tip cannot cut uniformly in porous areas and irregularities occur in the forces acting on the tool. Sudden force changes can be measured in porous or softer areas formed by the porous structure of the composite. It can be stated that this situation is more effective on feed force $F f$ and radial force Fr. At the same time, it was evaluated that the cutting tool could not perform uniform cutting in regions where there is CNT agglomeration in the composite structure. In regions where CNT agglomerating is intense, irregularities may occur in the forces acting on the cutting tool tip. In a study in the literature, it was stated that CNT aggregation affects not only mechanical properties but also machining properties [26].

The main factor that determines the power consumption during machining is the main cutting force. In addition, during machining, the feed rate value is known to be the most important parameter affecting the cutting forces and is in the literature [7]. For this purpose, the effect of feed rates on main cutting forces $F c$ according to CNTreinforcement ratios is also discussed. In the graphics in Fig. 11, main cutting forces $F c$ are given in the machining of $0 \%, 0.5 \%, 1.0 \%, 1.5 \%$ and $3.0 \%$ CNT-reinforced ZA-27 composite samples according to the feed rates. 

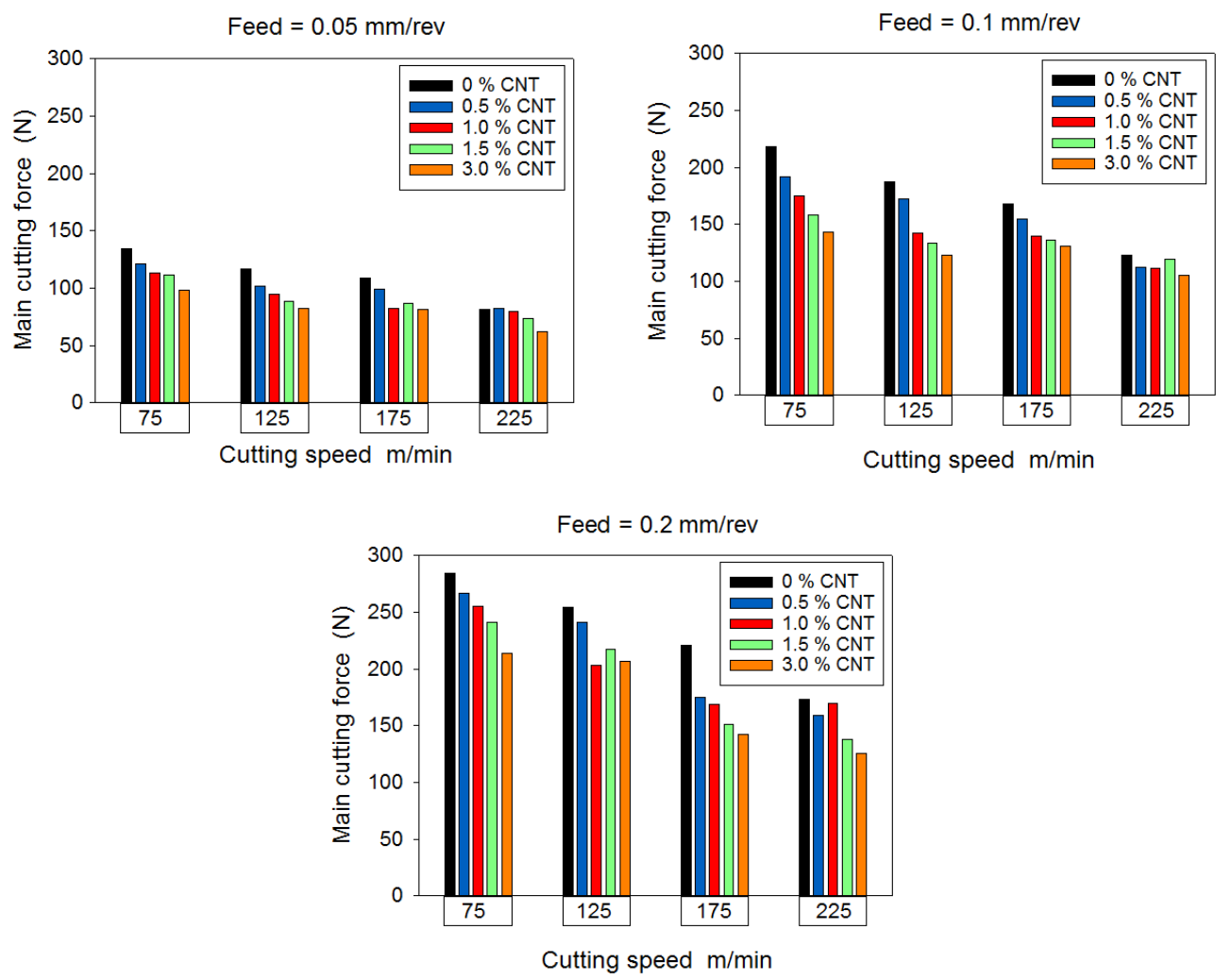

Fig. $11 F c$ main cutting forces according to feed rates in 0\%, 0.5\%, 1.0\%, 1.5\% and 3.0\% CNT-reinforced ZA27 composites

Chip cross section (A) relates to feed amount and depth of cut and can be calculated according to Eq. 6 .

$$
A=f \times a
$$

Where $(f)$ the feed rate is $(a)$ the depth of cut. Cutting forces also increase with increasing chip cross section (Eq.2). Therefore, increasing feed rates increase cutting forces. Looking at the graphs in Fig. 11, Fc main cutting forces also increased due to the increase in feed rate in all CNT-reinforcement ratios. The highest main cutting force was measured as $278 \mathrm{~N}$ in composite sample with $0 \%$ CNT-reinforced (pure ZA-27), cutting speed of 75 $\mathrm{m} / \mathrm{min}$ and feed rate of $0.20 \mathrm{~mm} / \mathrm{rev}$. The lowest main cutting force was recorded as $65 \mathrm{~N}$ at cutting speed of 225 $\mathrm{m} / \mathrm{min}$ and feed rate of $0.05 \mathrm{~mm} / \mathrm{rev}$ in 3.0\% CNT-reinforced composite sample. Due to the increase of the CNTreinforcement ratio, cutting forces decreased in all feed rates. The lubricating feature of the CNT-reinforcing material in the composite structure and the increase of porosity in the structure affected this situation. In addition, the increase in the CNT-reinforcement ratio and the decrease in the hardness and density of the composite structure were evaluated as additional factors. In a study in the literature, it is stated that with increasing graphite content, cutting flow stress decreases and reduces machining forces [27].

Another issue is the relationship between the rate of increase in feed rate and the rate of increase of main cutting force. The feed rate has increased by $100 \%$ each time. However, the main cutting force $F c$ did not change at the same ratio. For example, in the composite sample with $0 \%$ CNT-reinforcement, the $F c$ force at a cutting speed of $75 \mathrm{~m} / \mathrm{min}$ and a feed rate of $0.05 \mathrm{~mm} / \mathrm{rev}$ was $134 \mathrm{~N}$, while the $F c$ force at a feed rate of $0.10 \mathrm{~mm} / \mathrm{rev}$ was measured as $219 \mathrm{~N}$. Although the feed rate increased by $100 \%$, the main cutting force $F c$ increased by $63 \%$. At $0.20 \mathrm{~mm} / \mathrm{rev}$ feed rate, $F c$ force was measured as $278 \mathrm{~N}$. Here, the $F c$ force increased by $27 \%$ compared to the previous value of $0.10 \mathrm{~mm} / \mathrm{rev}$. Although there was $400 \%$ of increase between smallest feed rate of $0.05 \mathrm{~mm} / \mathrm{rev}$ and the largest feed rate of $0.20 \mathrm{~mm} / \mathrm{rev}$, main cutting force $F c$ increased by $105 \%$ in total. As a second example, we can examine the 3\% CNT-reinforced composite. While, the $F c$ force in $0.05 \mathrm{~mm} / \mathrm{rev}$ feed was $96 \mathrm{~N}$, the $F c$ force in $0.10 \mathrm{~mm} / \mathrm{rev}$ feed was measured as $141 \mathrm{~N}$. Although the feed amount increased by $100 \%$, the main cutting force $F c$ increased by $47 \%$. In the $0.20 \mathrm{~mm} / \mathrm{rev}$ feed, the $F c$ force was measured as $218 \mathrm{~N}$. Here, the $F c$ force increased by $55 \%$ compared to the $0.10 \mathrm{~mm} / \mathrm{rev}$ feed rate. Although there was $400 \%$ of increase between the smallest feed rate of $0.05 \mathrm{~mm} / \mathrm{revand}$ the largest feed rate of $0.20 \mathrm{~mm} / \mathrm{rev}$, main cutting force $F c$ has increased by $228 \%$ in total. According to these examples, it was concluded that the main cutting force $F c$ did not increase linearly with the increase in feed rates. It is understood from the graphs in Fig. 11 that composites in other CNT-reinforcement ratios can also be obtained approximately the same values. However, another 
conclusion was drawn from the two examples given above. It is also evaluated that the CNT nano material reinforced into the ZA-27 alloy causes unstable results on the main cutting forces $F c$.

\subsection{Evaluation of Surface Roughness}

The surface roughness (quality) value is an important parameter to decide the quality of the product and is also a very important factor for the machining process. Surface roughness in machining operations mainly depends on machining parameters such as cutting speed, feed rate, depth of cut, and cutting tool entering angle [23]. In machining, the average surface roughness $\mathrm{Ra}$ is usually taken into account. $\mathrm{Ra}$ is the arithmetic mean of the roughness values measured and is calculated according to Eq. 7.

$$
R a=\frac{1}{L} \int_{0}^{L}|Y(x)| d x
$$

Where $(R a)$ is the arithmetic mean of surface roughness values, $(L)$ sampling length, $(Y)$ profile curve coordinate. In Fig. 12, graphs drawn according to the average surface roughness values obtained from the machining tests of $0 \%, 0.5 \%, 1.0 \%, 1.5 \%$ and 3.0\% CNT-reinforced ZA-27 composite samples are given. The graphs show changes in the average surface roughness values for the feed rates of $0.05 \mathrm{~mm} / \mathrm{rev}, 0.10 \mathrm{~mm} / \mathrm{rev}$ and $0.20 \mathrm{~mm} / \mathrm{rev}$, depending on the cutting speeds of $75,125,175$ and $225 \mathrm{~m} / \mathrm{min}(R a)$.
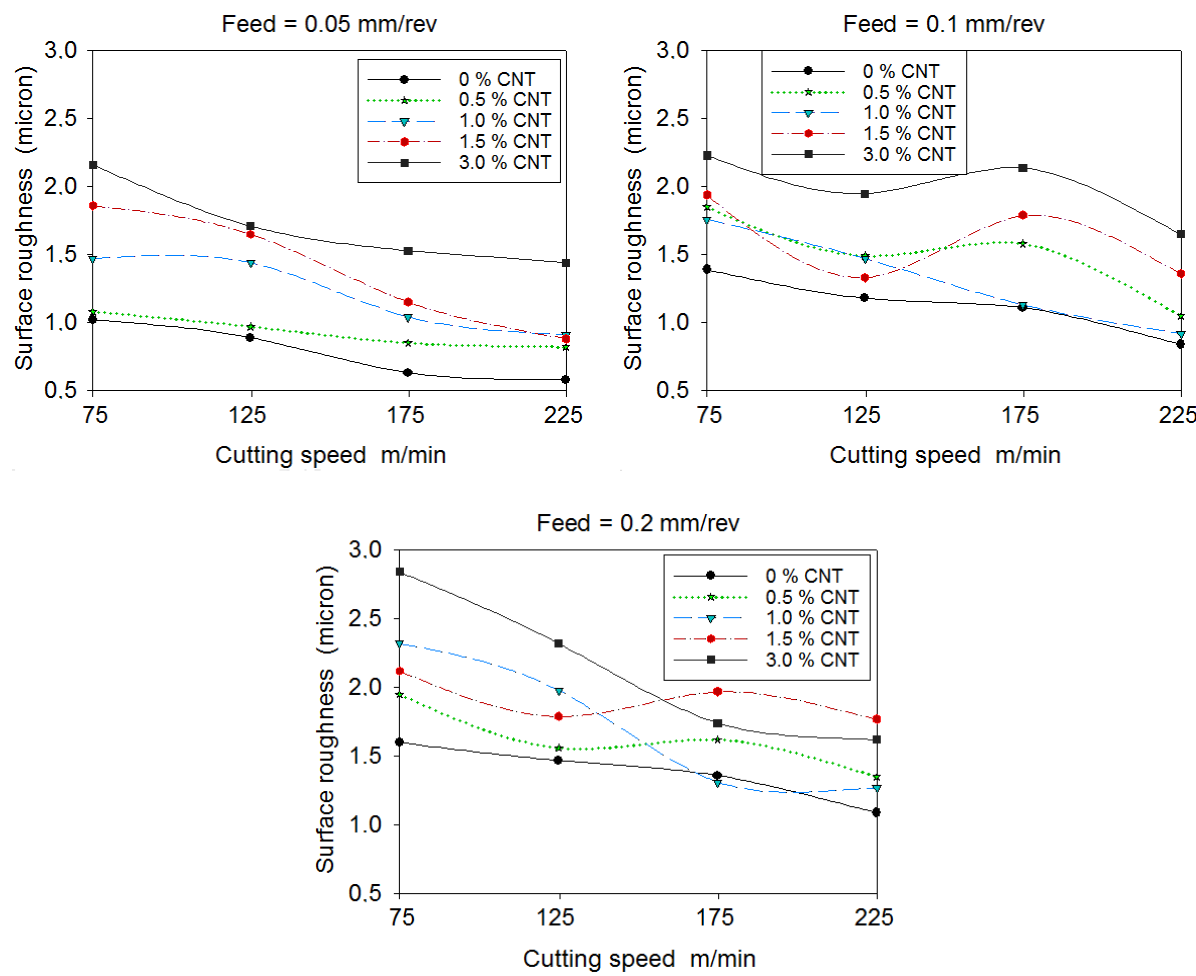

Fig. 12 Surface roughness amounts according to feed in $0 \%, 0.5 \%, 1.0 \%, 1.5 \%$ and $3.0 \%$ CNT-reinforced ZA-27 composites

Looking at the graphs in Fig. 12, it is understood that the most important parameters affecting surface roughness amounts are cutting speed and feed rate. In a study in the literature, it was stated that surface roughness mainly depends on the feed rate and then the cutting speed [23]. In the graphics in Fig. 12, it is seen as a general trend that the surface roughness values decrease with increasing cutting speed. There are studies reporting similar results in the literature [21]. Another issue that affects the quality of the machined surfaces is the temperature that occurs during cutting. Considering the tool-workpiece and tool-chip interaction, the temperature in the cutting zone increases due to the increase in cutting speed. With this temperature increase, plastic deformation is easier in the primary deformation zone, while in the secondary deformation zone, the chip flow is facilitated. This positively affects the surface quality as expected and causes a decrease in surface roughness [28]. Fig. 13 shows the deformation zones formed during the metal cutting process. 


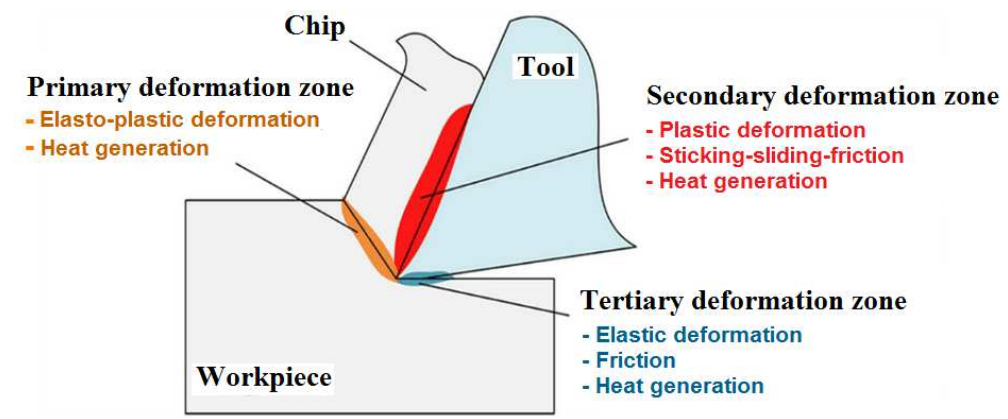

Fig. 13 Sources of heat generation in the orthogonal cutting process [29]

As seen in Fig. 13, heat occurs in three regions during metal removal. The workpiece is exposed to excessive strain in the primary deformation zone. The energy spent for this strain is much higher than the energy spent for elastic deformation. Therefore, it can be assumed that almost all of the mechanical energy is converted into heat. For this reason, the heat generated in the cutting zone can be considered as a very important factor as it affects tool performance and workpiece surface quality. In a study examining the relationship between cutting speed and surface roughness, it is stated that surface roughness decreases with increasing cutting speed at different cutting depth and constant feed rate [3]. It has been stated in the studies that the most effective parameter on the surface roughness values is the speed of progress [30-33]. In this study, in order to discuss the effect of feed rates on surface roughness values in more detail, the graphics in Fig. 14 were created.
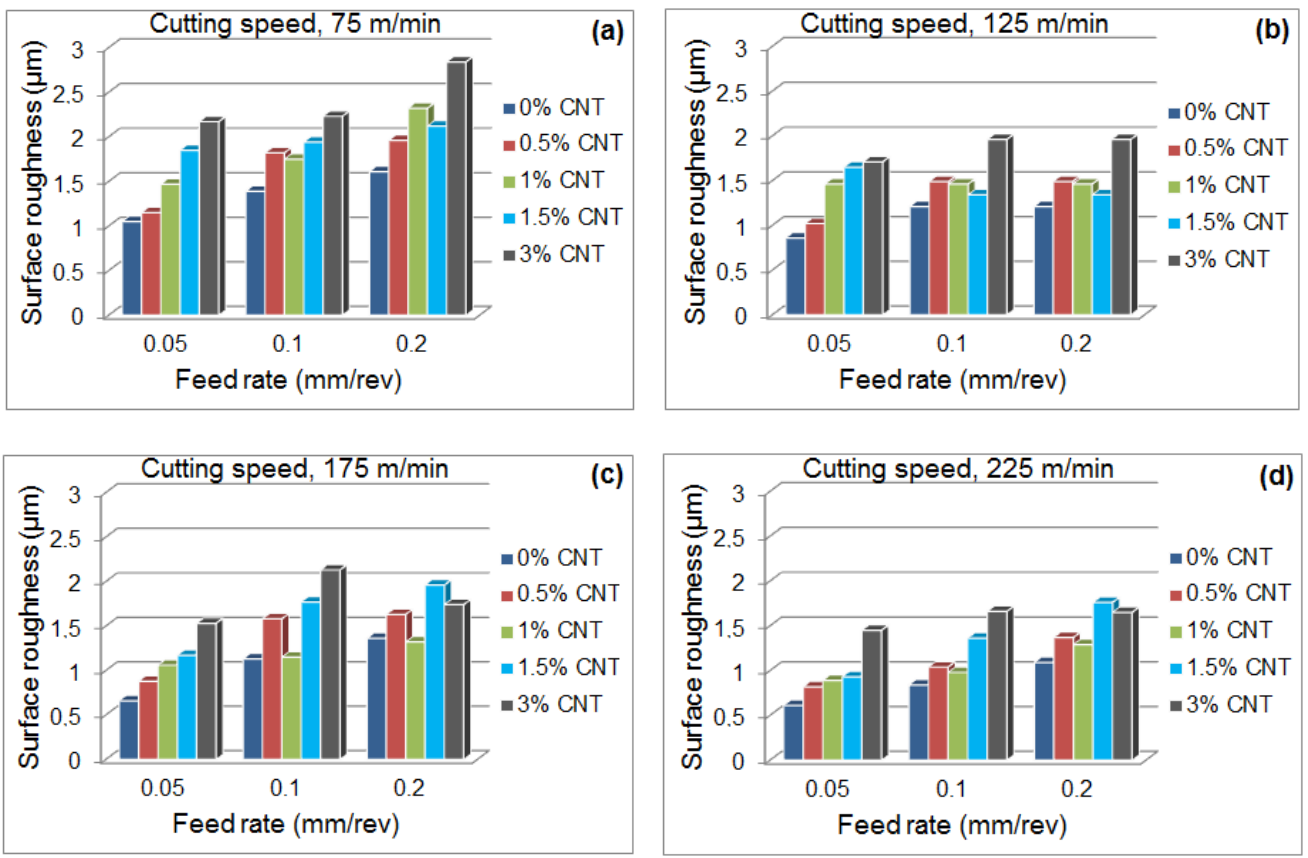

Fig. 14 Surface roughness amounts according to the cutting speed in $0 \%, 0.5 \%, 1.0 \%, 1.5 \%$ and $3.0 \%$ CNTreinforced ZA-27 composites

Looking at the graphs in Fig. 14, it seems clearer that the surface roughness value decreases with increasing cutting speed, and the roughness values increase with increasing feed rate. Along with the feed rate, the corner radius (cutting edge radius) of the cutting tool used in machining tests is another important factor affecting the surface roughness [34]. In Fig. 15, the surface roughness mechanism that occurs depending on the feed rate and tool nose radius is shown. 


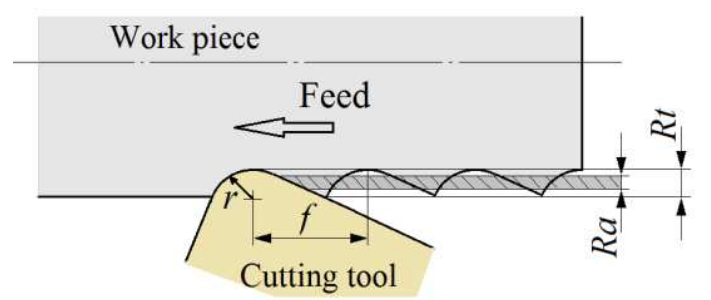

Fig. 15 Surface roughness relationship with tool nose radius in machining

In turning, the calculation of the surface roughness in relation to the tool nose radius is made according to Eq. 8 .

$$
R t=\frac{f^{2}}{8 r} \times 10
$$

Where $(f)$ feed rate, $(r)$ cutting edge radius, $(R t)$ surface roughness. As can be seen, the feed rate is one of the most important factors that directly affect the surface roughness value. Therefore, as the nose radius of the cutting tool cannot sweep the surface with increasing feed rate, machining scratches occur on the parts where the tool tip cannot contact the surface. The height of these scratches is $R t$, which is the largest roughness value. By calculating the arithmetic means of the $R t$ values obtained, the average surface roughness value $R a$ is determined. The average surface roughness value in the turning process using a single-edged cutting tool is calculated by Eq. 9 .

$$
R a=\frac{f^{2}}{32 r}
$$

Where $(f)$ is the advance, $(r)$ the cutting edge radius, $(R a)$ is the average surface roughness. As can be seen from the SEM images in Fig. 5, CNT-reinforcement material could not be distributed in the desired homogeneity within the composite structure. Especially with the increase of the CNT-reinforcement to $1.5 \%$ and $3 \%$ the roughness of the composites increased significantly Fig. $5 \mathrm{c}$ and $\mathrm{d}$. In a study in the literature, it is stated that CNT-reinforcement above $0.5 \%$ negatively affects the machinability and mechanical properties [35]. The similar result was highlighted in another study in the literature [36]. This undesired situation is considered to be caused primarily by CNT-reinforcement agglomerates. In areas where reinforcement agglomerates occur during chip removal, when the cutting tool tip meets the pore or the soft phase with the CNT agglomeration cutting behavior of the tool changes and the surface roughness changes. Porous areas have also occurred in areas with CNT agglomeration due to the removal of CNT materials from the surface during machining. The CNT additive increased the surface roughness values of the ZA-27 alloy and negatively affected the surface quality of the machined composites. It has been stated that graphite increases surface roughness. It is stated that this is caused by the smearing or removal of soft and amorphous graphite particles on the surface of the sample. It is emphasized that the cavities formed by the graphite particles moving away from the surface increase the surface roughness values [37].

Another important issue is the low surface roughness values in pure ZA-27 matrix material without CNTreinforcement. In a study in the literature, it was stated that the surface of the composite material was more rough than the graphite-free alloy due to the removal of graphite particles on the machined surfaces of the composite or the grooves formed by the graphite particles behind the moving tool tip [27]. In the pure ZA-27 material without CNT-reinforcement, the surface roughness was obtained at half value lower than $3 \%$ CNT-reinforced composite. For example, in the experiment performed at a cutting speed of $75 \mathrm{~m} / \mathrm{min}$ and a feed rate of $0.05 \mathrm{~mm} / \mathrm{rev}$, the average surface roughness value $(R a)$ was measured at $2.17 \mu \mathrm{m}$ (micron) in the $3 \%$ CNT-reinforced nano composite. In the same experiment, the average surface roughness value $(R a)$ was measured as $1.05 \mu \mathrm{m}$ in the pure ZA-27 sample without CNT-reinforcement. However, some instability has been noted in the range of roughness value with feed rate changes. For example, at a cutting speed of $75 \mathrm{~m} / \mathrm{min}$ and $0.1 \mathrm{~mm} / \mathrm{rev}$ feed, while the average surface roughness value in the 3\% CNT-reinforced nano composite was $2.23 \mu \mathrm{m}$, the average surface roughness value in the pure ZA-27 sample without CNT-reinforcement was $1.33 \mu \mathrm{m}$. Lastly, in the experiment performed at a cutting speed of $75 \mathrm{~m} / \mathrm{min}$ and a feed rate of $0.2 \mathrm{~mm} / \mathrm{rev}$, while the average surface roughness value in 3\% CNT-reinforced nano composite was $2.84 \mu \mathrm{m}$, the average surface roughness value in the pure ZA-27 sample without CNT-reinforcement was measured as $1.61 \mu \mathrm{m}$. As shown in the examples, the differences between the roughness values of 3\% CNT-reinforced samples and pure ZA-27 samples without CNT-reinforcement decreased with increasing feed rates.This situation is thought to be caused primarily by the increase in the amount of chip removed. It caused the thermal softening with the temperature increasing on the material surface due to the increase in the amount of chip and increased cutting forces. During machining on the surface of softened material, it is evaluated that the ZA-27 matrix material is smeared to the pores together with 
the tool tip moving. With this smearing, it is thought that some of the pores in the composite structure may have been sealed and therefore the surface roughness values have decreased slightly. Another issue that affects the surface roughness values is the BUE occurring at the cutting tool tip. In a study, it was stated that the BUE formed at the cutting tool tip had an important effect on the roughness of the machined surfaces [19].

In addition, it can be stated that the BUE formed at the cutting tool behaves like a cutting edge. It can be said that this situation prevents some wear on the tools. However, it can also be said when it has a negative effect on the roughness values and quality of the treated surfaces. It can be stated that the hard phase reinforcement particles that may be embedded in BUE and BUE at the tool tip can scratch the surfaces during machining experiments. In addition, it is thought that the BUE mass consisting of the ZA-27 alloy in the soft phase at the tool tip contributes to the increase of the roughness values by plastering the treated surfaces with the effect of the temperature.

It is known that another aspect affecting the roughness of the composite structure is the production method of the composite. In powder metallurgy method, slightly more hollow structure can be formed when compared to liquid phase production methods. In areas where the bonding between the grains is weak due to the incomplete sintering process, ZA-27 particles can be removed from each other or broken and formed pores in the composite structure during machining. In addition, there are CNT particles in the composite structure that are located between ZA-27 grains and are heavily agglomerated. Since the intergranular bonding is very weak in these regions, larger amounts of material removal may occur. With this CNT and ZA-27 removal, carved regions are formed on the machined surface. Therefore, during the roughness measurement, when the probe of the measuring device over the cavity areas, there may be increases in surface roughness values or some instability. Looking at the graphics in Fig. 10 and Fig. 12, these instabilities are seen. However, in a study in the literature, it was stated that the porosity factor in materials produced by powder metallurgy can help break down chips during machining [33]. According to the literature, this interpretation can be considered an advantage for the powder metallurgy method compared to the liquid phase methods.

\section{Conclusions}

The results obtained from the examinations of CNT-reinforced ZA-27 matrix composites produced by the powder metelurgy method and whose machinability tests are performed are listed below.

1. With the increase of CNT-reinforcement ratio, hardness values of ZA-27 nano composites decreased and pore amounts increased. Especially at CNT-reinforcement ratios of $1.5 \%$ and above, there was a significant increase in the pore amount of the composite structure.

2. The reduction of the hardness of the composite by the CNT-reinforcement reduced the mechanical strength. On the other hand, it had a positive effect on machinability by reducing cutting forces.

3. Since the increase in feed rates increases the cross section, cutting forces and surface roughness have increased accordingly.

4. With the increase of cutting speed, temperature increase has occurred in the cutting region. With the effect of plastic deformation and thermal softening caused by increasing temperature, friction in the tool-chip interface has decreased and chip flow has been relieved. As a result, cutting forces and surface roughness levels have decreased.

5. CNT, which is a graphite based reinforcing material, has a lubricating effect, somewhat relieved the cutting process and caused the cutting forces to decrease.

6. The rate of increase in feed rates and increases in main cutting forces were not linear. Although the amount of feed rate has increased by $100 \%$ each time, the increase in Fc main cutting forces has been around $50 \%$. It was evaluated that this positive result was caused by the lubricating effect of the CNT-reinforcement in dry cutting conditions and the depth of the cutting being in accordance with the tool nose radius.

7. With the increase of CNT-reinforcement ratio in the composite structure, the roughness values on the machined surfaces increased.

8. BUE has occurred in most cutting tools. At the same time, BUE amounts increased as the feed rate increased. The resulting BUE increased the surface roughness values.

10. In homogeneous distribution and partial aggregation of CNT-reinforcing material in the composite structure has been evaluated to cause some instability in both cutting forces and surface roughness values.

11. With the data obtained from this experimental study, it was concluded that the CNT-reinforcement in the ZA-27 alloy has a positive effect on the cutting forces and reduces the machine power spent.

12. In addition, when cutting forces and surface quality are evaluated together in the machining of such composites, it can be recommended not to increase the CNT-reinforcement ratio above $1 \%$.

Conflict of interest Author declares that he has no conflict of interest. 
Consent to Publish The authors agreed to publish.

Authors Contributions Muharrem Pul is the sole author of this paper.

Funding No funds were used in this study.

Competing Interests There is no competitive conflict.

Consent to Participate Not applicable.

Availability of data and materials Data sharing is not applicable to this article as no new data were created in this study.

\section{References}

1. Pul M. Effect of sintering temperature on pore ratio and mechanical properties of composite structure in nano graphene reinforced ZA27 based composites. International Journal of Minerals, Metallurgy and Materials 2020; 27(2):232-243.

2. Kaushik BK, Majumder MK. Carbon Nanotube Based VLSI Interconnects: Analysis and Design. Springer Briefs in Applied Sciences and Technology 2015; 17-37.

3. Balki N, Nelge B, Dr. Ingle A. Experimental Investigation Of Environment Friendly Cooling Methods For Different Machining Conditions. International Journal Of Engineering Sciences \& Research Technology 2017; 6(11): 186-191.

4. https://www.researchgate.net/Fig./Graphene-and-carbon-nanotubes-as-A-single-wall-carbon-nanotubeSWCNT-and-B_fig1_263740854

5. Tekaslan Ö, Gerger N, Günay M, Seker U. Examination Of The Cutting Forces Of AISI 304 Austenitic Stainless Steel In The Turning Process With Titanium Carbide Coated Cutting Tools. Pamukkale University Engineering College, Journal Of Engineering Sciences 2007; 13(2): 135-144.

6. Punit SV, Kamlesh PK. Parametric Optimization of Cutting Force and Temperature During Hard Turning of Inconel 625-A Review.IJIRST -International Journal for Innovative Research in Science \& Technology 2015; 1(8): 17-20.

7. Korka ZI, Miclosină C-O, Cojocaru V. An Experimental Study of the Cutting Forces in Metal Turning. Analele Universităłıi "Eftımie Murgu" Reşiła Anul XX NR.2 2013; 25-32.

8. Dalmış R, Çuvalcı H, Çanakcı A, Güler O. Investigation of Graphite Nano Particle Addition on The Physical and Mechanical Properties Of ZA27 Composites. Advanced Composites Letters 2016; 25(2): 3742.

9. El-Sayed Sherif M, Latief FH, Junaedi H, Almajid AA. Influence of Exfoliated Graphite Nanoplatelets Particles Additions and Sintering Temperature on the Mechanical Properties of Aluminum Matrix Composites. Int. J. Electrochem. Sci. 2012; 7: 4352-4361.

10. Şenel MC, Gürbüz M, Koç E. The fabrication and characterization of graphene reinforced aluminum composites. Pamukkale University Journal of Engineering Sciences 2017; 23( 8): 974-978.

11. Saheb N, Khalil A, Hakeem AS, Laoui T, Al-Aqeeli N. Carbon Nanotube Reinforced Al6061 and Al2124 Nanocomposites. ECCM15 -15th European Conference on Composite Materials, Venice, Italy, 24-28 June 2012,pp. 1-8.

12. Zhou M, Qu X, Ren L, Fan L, Zhang Y, Guo Y, Quan G, Tang Q, Liu B, Sun H.The Effects of Carbon Nanotubes on the Mechanical and Wear Properties of AZ31 Alloy. Materials 2017; 10: 1385.

13. Garg P, Gupta P, Kumar D, Parkash O. Structural and Mechanical Properties of Graphene reinforced Aluminum Matrix Composites. J. Mater. Environ. Sci.2016; 7(5): 1461-1473.

14. Shoba Ch, Ramanaiah N, Nageswara Rao D. Effect of reinforcement on the cutting forces while machining metal matrix compositese An experimental approach. Engineering Science and Technology,an International Journal 2015; 18: 658-663.

15. Günay M. Experimental investigation of the effect of cutting tool chip angle on cutting forces in chip removal process.Master Thesis, Gazi University Institute of Science 2003,Ankara, Turkey, (In Turkish).

16. Sandvik C. Modern metal cutting: A practical handbook (English edition). Sandviken: Sandvik Coromant, 1994; pp.I-III.

17. Mannaa A, Bhattacharayya B. A study on machinability of Al/SiC-MMC. Journal of Materials Processing Technology 2003; 140:711-716. 
18. Sekmen M, Günay M, Şeker U. Effect on Formations of Built-up Edge and Built-up Layer, Surface Roughness of Cutting Speed and Rake Angle in the Machining of Aluminum Alloys. Journal of Polytechnic 2015; 18(3): 141-148.

19. Özçatalbaş Y. Chip and built-up edge formation in the machining of in situ Al4C3-Al composite. Materials and Design 2003; 24: 215-221.

20. Gökkaya H, Nalbant M. Investigating The Effects Of Cutting Speeds Over The Built-Up Layer And BuiltUp Edge Formation With SEM, J. Fac. Eng. Arch. Gazi Univ. 2007; 22(3): 481-488.

21. Nas E, Gökkaya H. Experimental and Statistical Study on Machinability of the Composite Materials with Metal Matrix Al/B4C/Graphite. Metallurgical And Materials Transactions A. 2017; 48A: 5059-5067.

22. Gnanavelbabu, A., Arunachalam, V., Sunu, Surendran, K.T., Rajkumar, K.: Optimization of machining parameters in CNC turning of AA6061-B4C-CNT hybrid composites using Grey-fuzzy Method.IOP Conf. Series: Materials Science and Engineering 2020; 764: 012010.

23. Xavior Ma A, Kumar J Pb A.Machinability of Hybrid Metal Matrix Composite - A Review. Procedia Engineering 2017; 174: 1110-1118.

24. Zhang H. Plastic Deformation and chip Formation Mechanics during Machining of Copper, Aluminium and an Aluminium Matrix Composite. PhD. Thesis, University of Windsor 2000; Canada.

25. Günay M. Investigation of mechanical and machinability properties of $\mathrm{Al}-\mathrm{Si} / \mathrm{SiCp}$ composites produced by powder metallurgy method. Ph.D. Thesis, Gazi University Institute of Science 2009; Ankara, Turkey

26. Islam Rubel R, Hasan Ali Md, Md. Jafor A, Mahmodul Alam Md. Carbon nanotubes gglomeration in reinforced composites: A review. AIMS Materials Science 2019; 6(5): 756-780.

27. Brown CA and Surappa MK. The machinability of a cast Aluminium alloy-Graphite Particle composite. Material Science Engineering A. 1988; 102(1): 31-37.

28. Pul M, Uzun G, Şeker U.Investigation Of Machinability Of Al2024 Matrix MgO+SiC Reinforced Hybrid Composites In Terms Of Surface Quality. 10th International Congress On Machining, Antalya, Turkey, 27 29 November 2019, pp.223-229.

29. Latha Shankar B, Anil KC, J Karabasappagol P. A Study on Effect of Graphite Particles on Tensile, Hardness and Machinability of Aluminium 8011 Matrix Material.IOP Conf. Series: Materials Science and Engineering 2016;149: 012060.

30. Ranganath MS, Vipin,. Mishra RS, Prateek, Nikhil. Optimization of Surface Roughness in CNC Turning of Aluminium 6061 Using Taguchi Techniques. International Journal of Modern Engineering Research (IJMER) 2015; 5: 42-50.

31. Deepak D, Rajendra B. Investigations on the surface roughness produced in turning of Al 6061 (as-cast) by taguchi method. International Journal of Research in Engineering and Technology 2015; 4: 295-298.

32. Pridhvijit A, Binu CY. Experimental Study and Parameter Optimization of Turning Operation of Aluminium Alloy-2014. International Journal of Engineering Researchand General Science. 2015; 3: 525530.

33. Rogov VA, Siamak G. Optimization of Surface Roughness and Vibration in Turning of Aluminum Alloy AA2024 Using Taguchi Technique. International Journal of Mechanical, Aerospace, Industrial, Mechatronic and Manufacturing Engineering2013; 7: 2330-2339.

34. Satheesh J, Tajamul Pasha, Harish, Madhusudhan T. Optimal MachiningConditionsForTurning Of AlSiC Metal Matrix Composites Using ANOVA. International Journal of Innovative Research in Science, Engineering and Technology 2013; 2(11) 6171-6176.

35. Nandakumar A, Dinakaran D.Effect of Nano Particles in reinforced metal Matrix Composite onthe machinability characteristics- A Review.Applied Mechanics and Materials. 2015; (813-814): 625-628.

36. Umashankar KS, Gangadharan KV, Desai V, Shivamurthy B. Machining characteristics of nano composites. Advanced Materials Letters 2011;2(3): 222-226.

37. Basavarajappa S, Paulo Davim J.Influence of Graphite Particles on Surface Roughness and Chip Formation Studies in Turning Metal Matrix Composites. Materials Research 2013; 16(5): 990-996. 


\section{Figures}

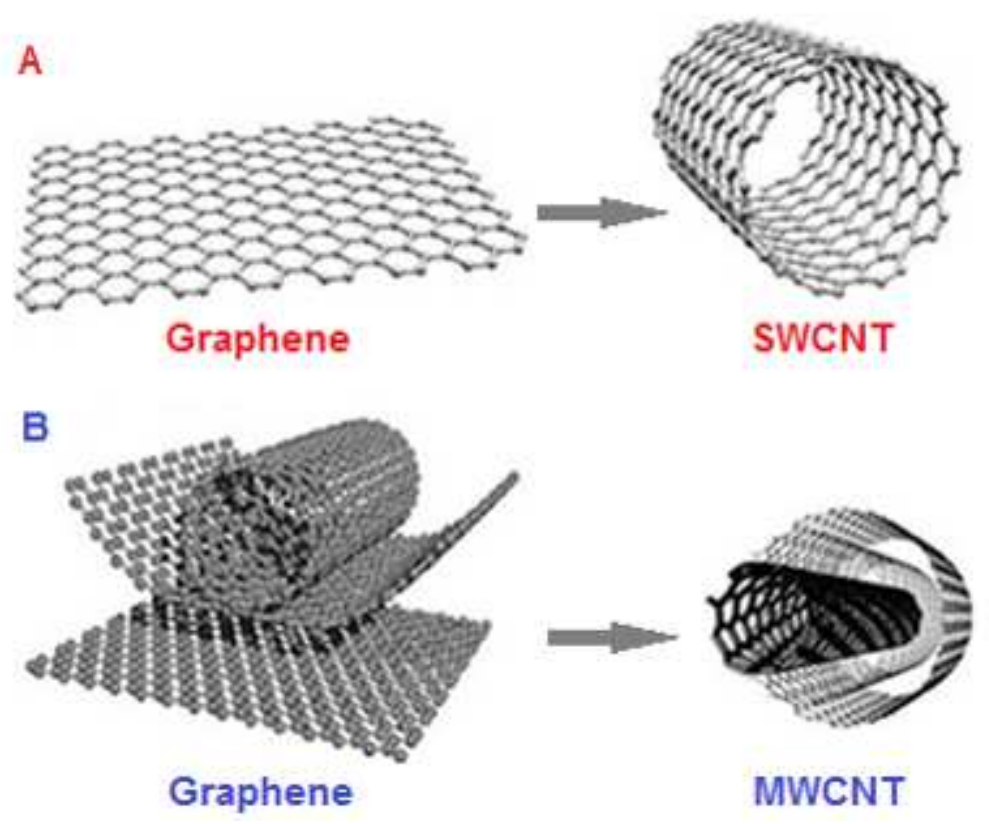

\section{Figure 1}

Graphene and carbon nanotubes as (A) single wall carbon nanotube (SWCNT) and (B) multi-wall carbon nanotube (MWCNT) structures [4]

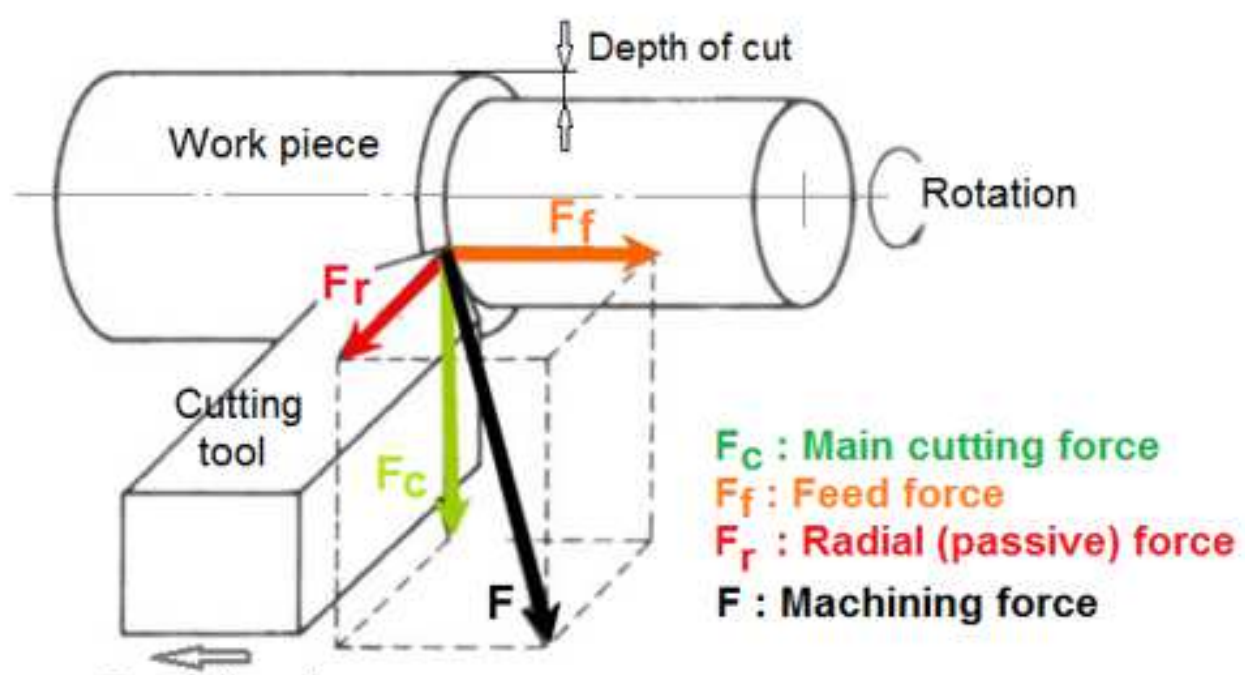

Feed direction

Figure 2

Cutting force components in turning [6] 


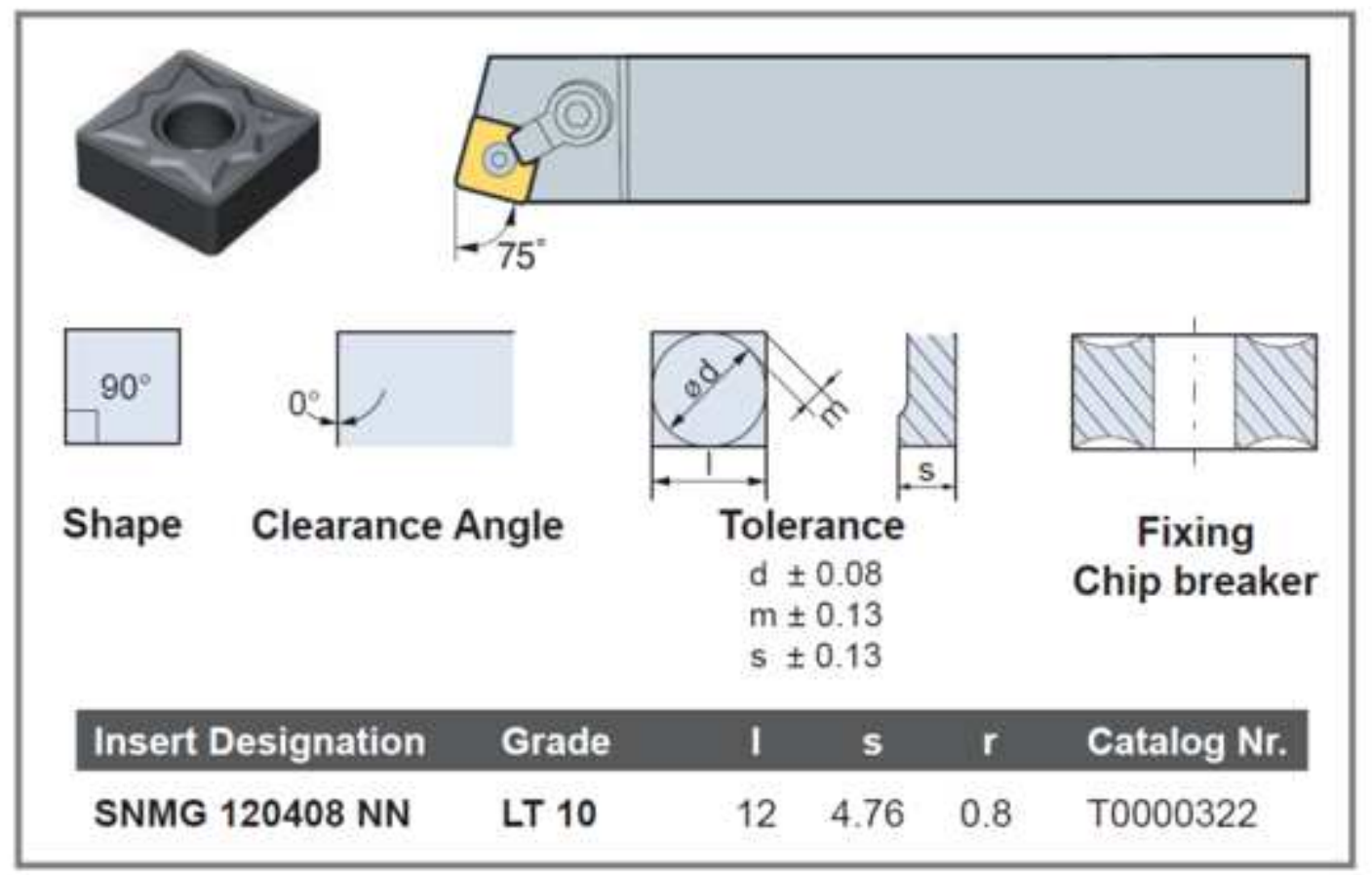

Figure 3

Cutting tool and tool holder used in machining tests

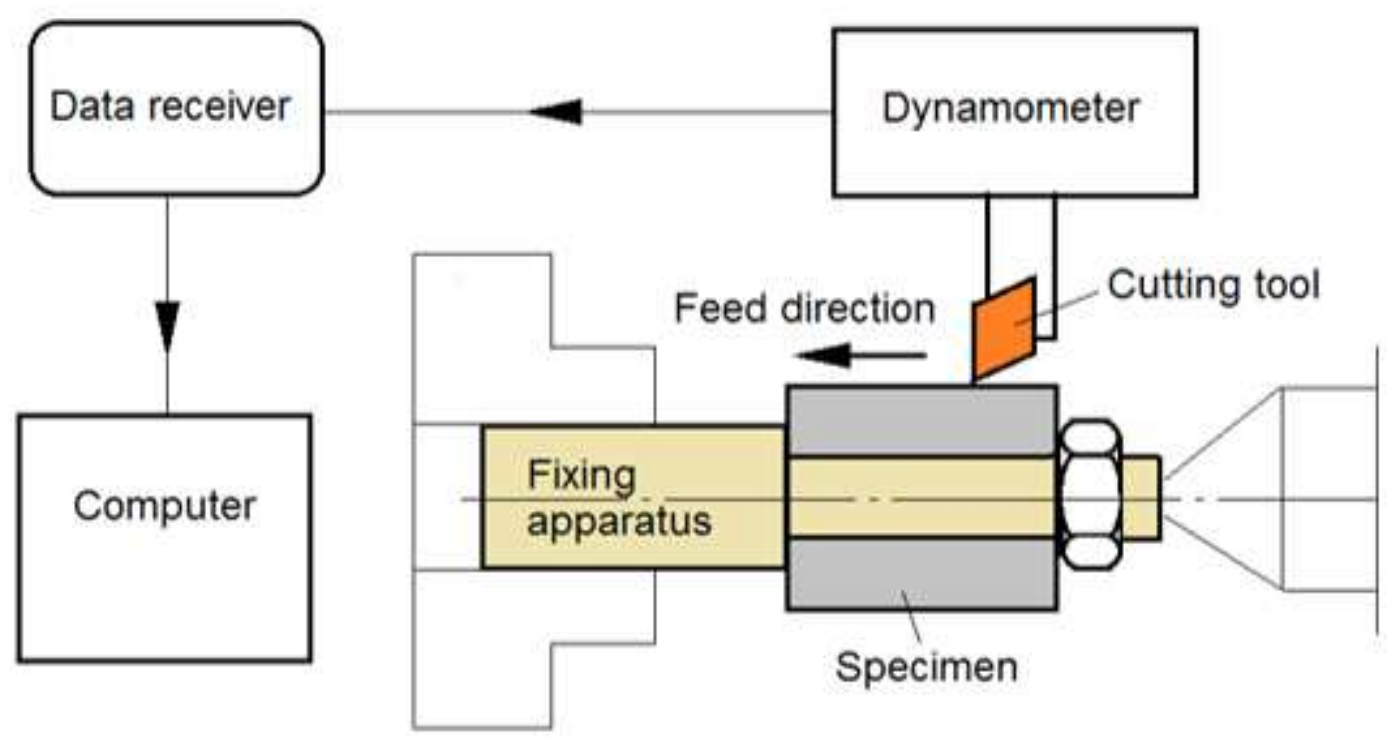

Figure 4

Machining test setup 

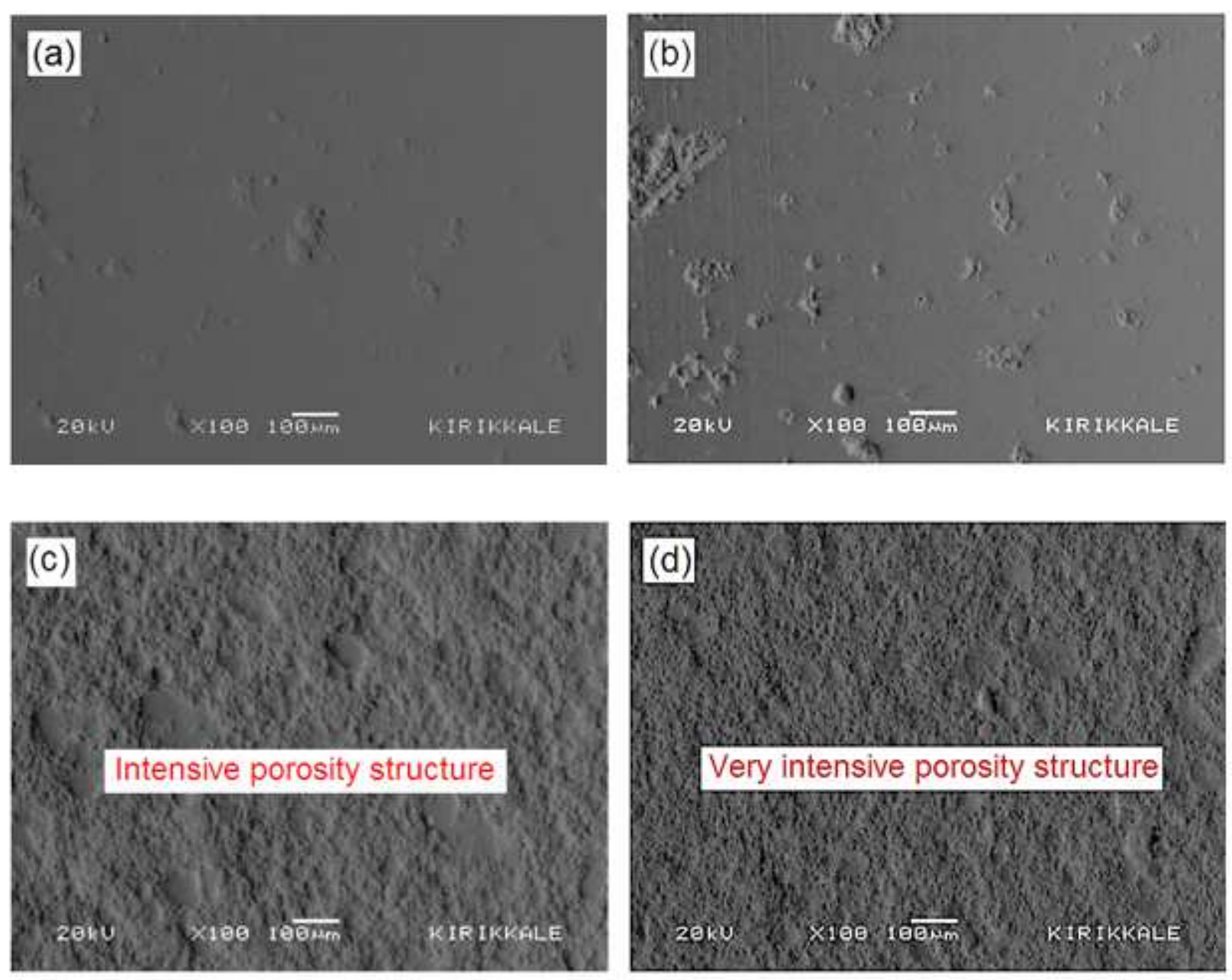

\section{Figure 5}

Microstructures of $0.5 \%$ CNT (a), 1.0\% CNT (b), 1.5\% CNT (c), 3.0\% CNT (d) reinforced ZA-27 matrix nano composites
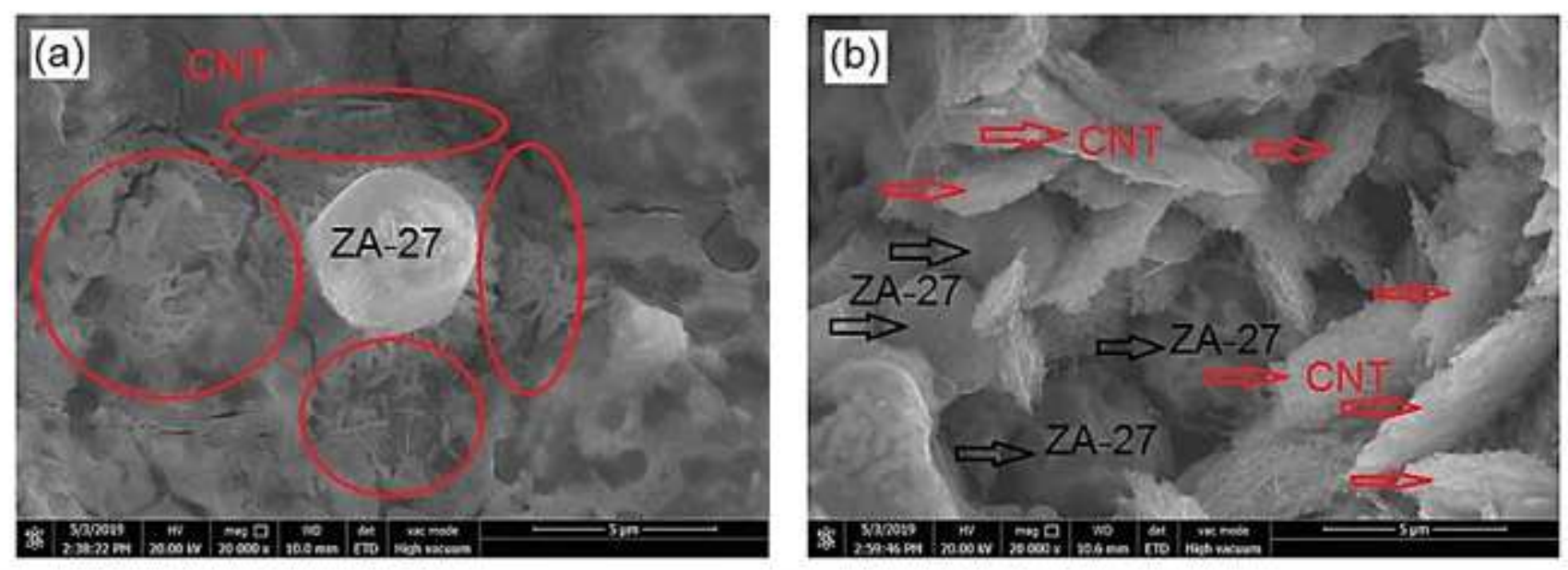

Figure 6

CNT-reinforcing elements in composite structure 

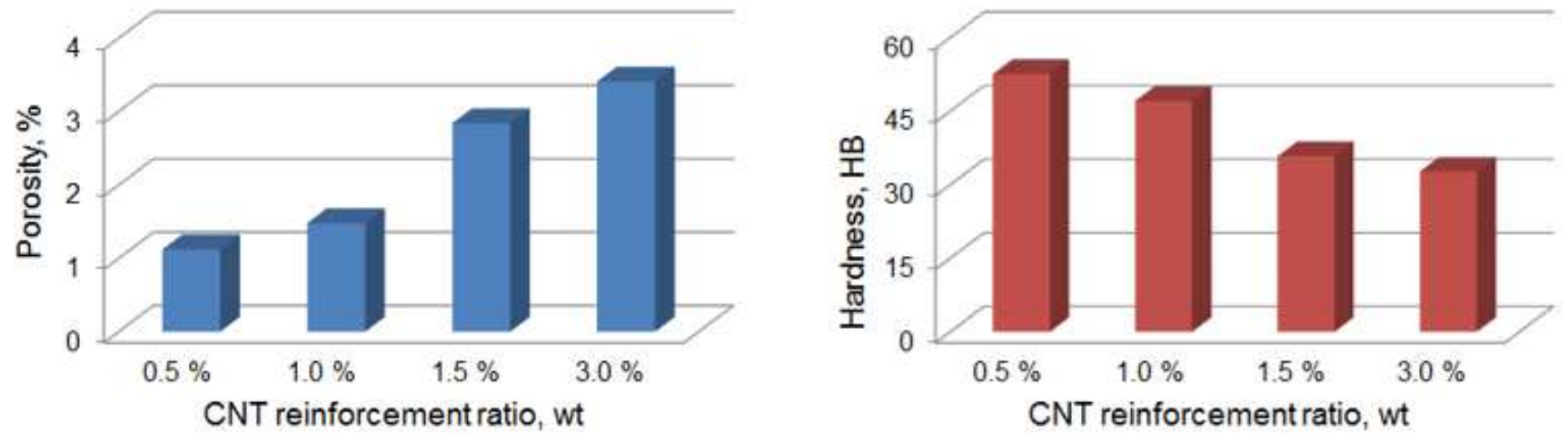

Figure 7

Hardness and porosity amounts of Nano CNT-reinforced ZA-27 composites. 

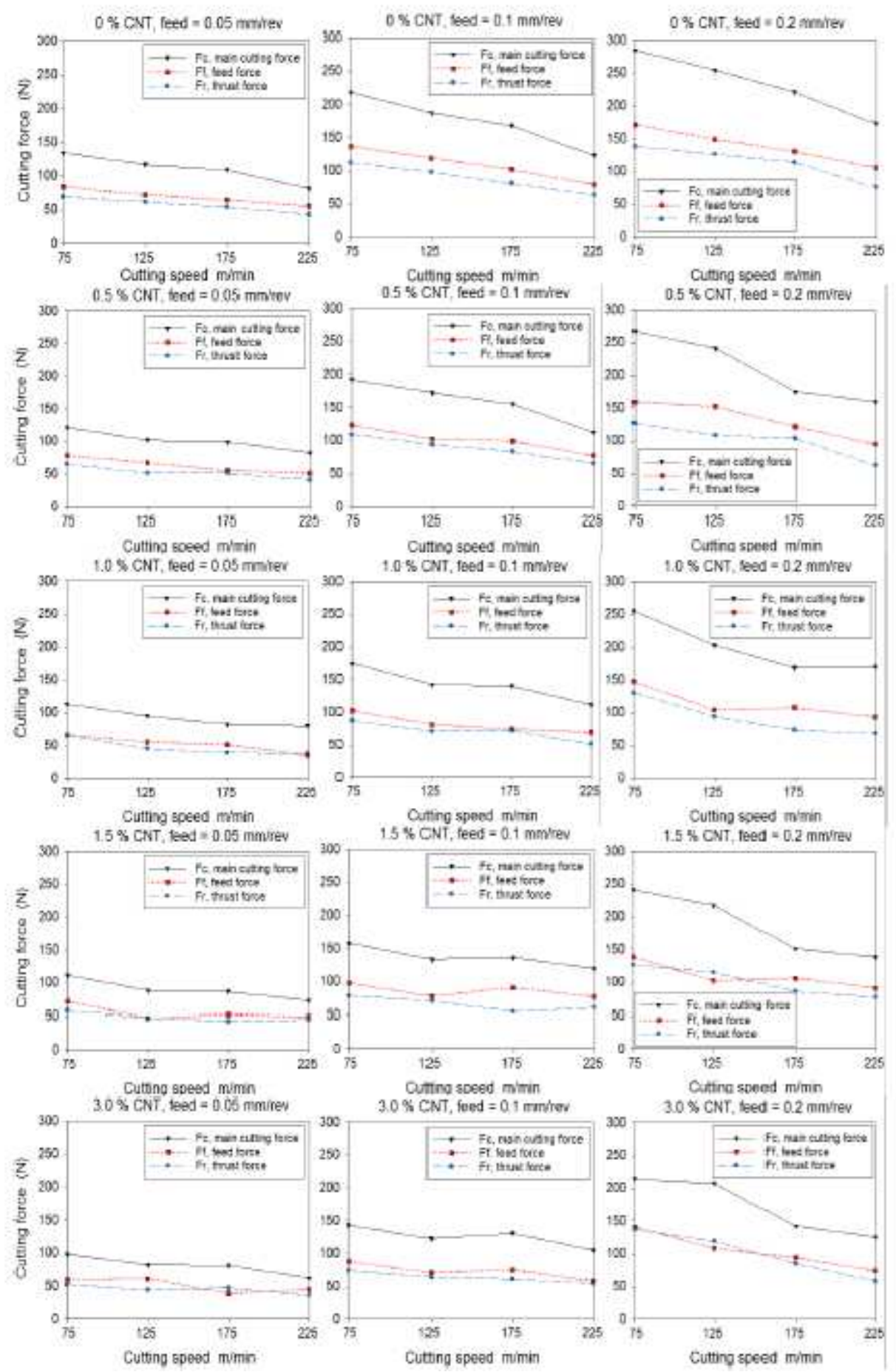

\section{Figure 8}

Cutting forces measured in CNT/ZA-27 composites depending on feed and cutting speed. 


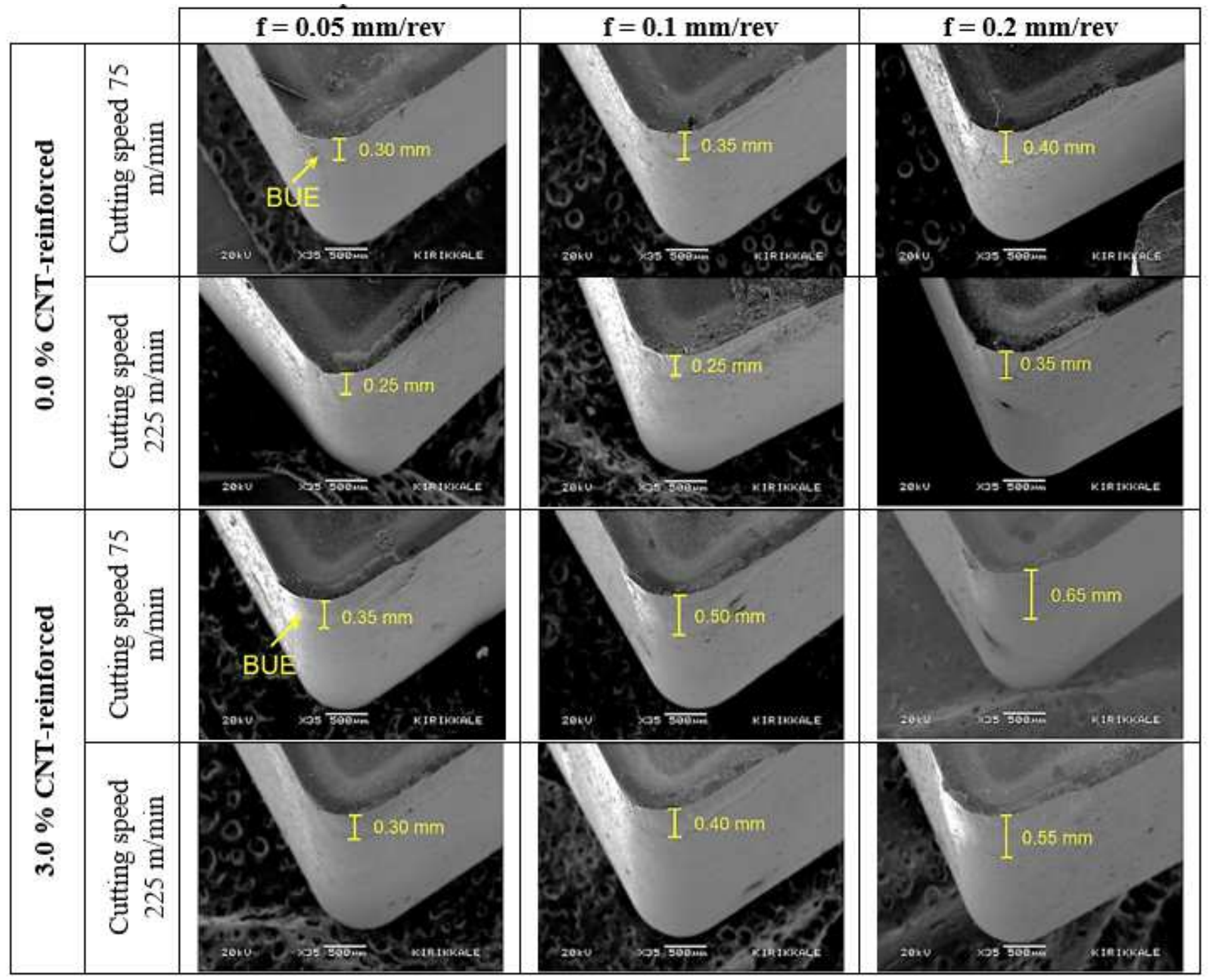

Figure 9

Cutting tools used in $0 \%$ and $3 \%$ CNT-reinforced composites machined at a cutting speed of $75 \mathrm{~m} / \mathrm{min}$, $225 \mathrm{~m} / \mathrm{min}$ and feed rate of $0.05 \mathrm{~mm} / \mathrm{rev}, 0.1 \mathrm{~mm} / \mathrm{rev}, 0.2 \mathrm{~mm} / \mathrm{rev}$

(a)

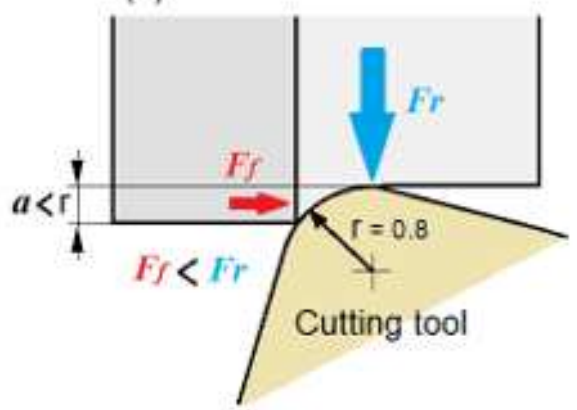

(b)

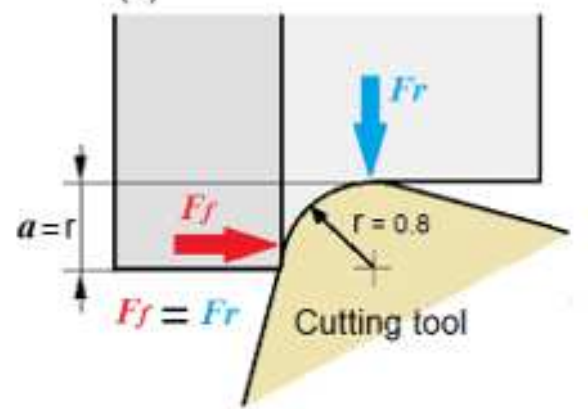

(c)

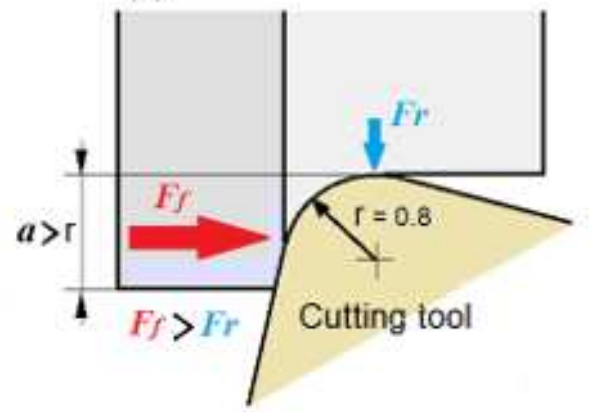

Figure 10 
Representation of the direction of the forces received by the tool when machining below and above the nose radius.
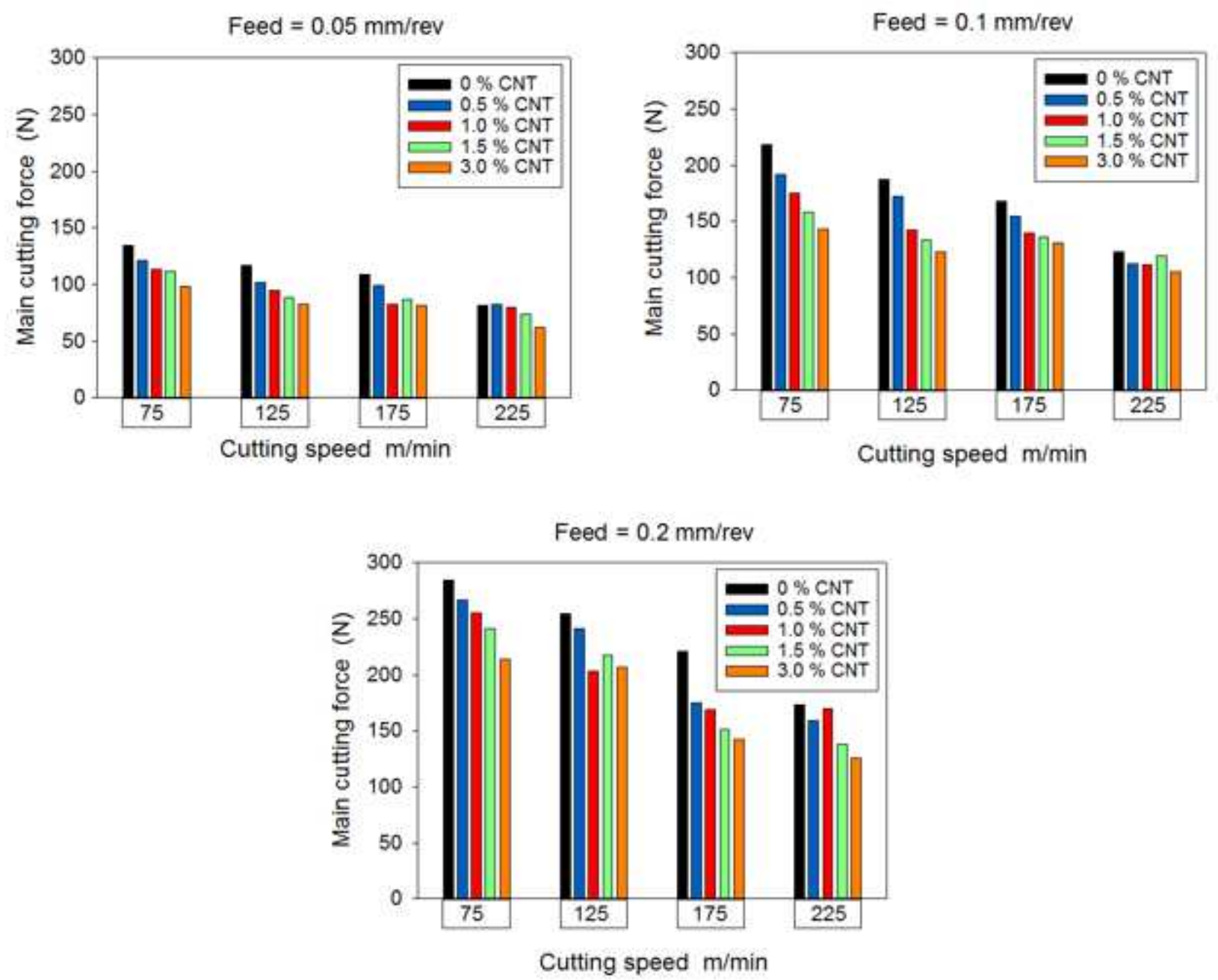

Figure 11

Fc main cutting forces according to feed rates in $0 \%, 0.5 \%, 1.0 \%, 1.5 \%$ and $3.0 \%$ CNT-reinforced ZA-27 composites 

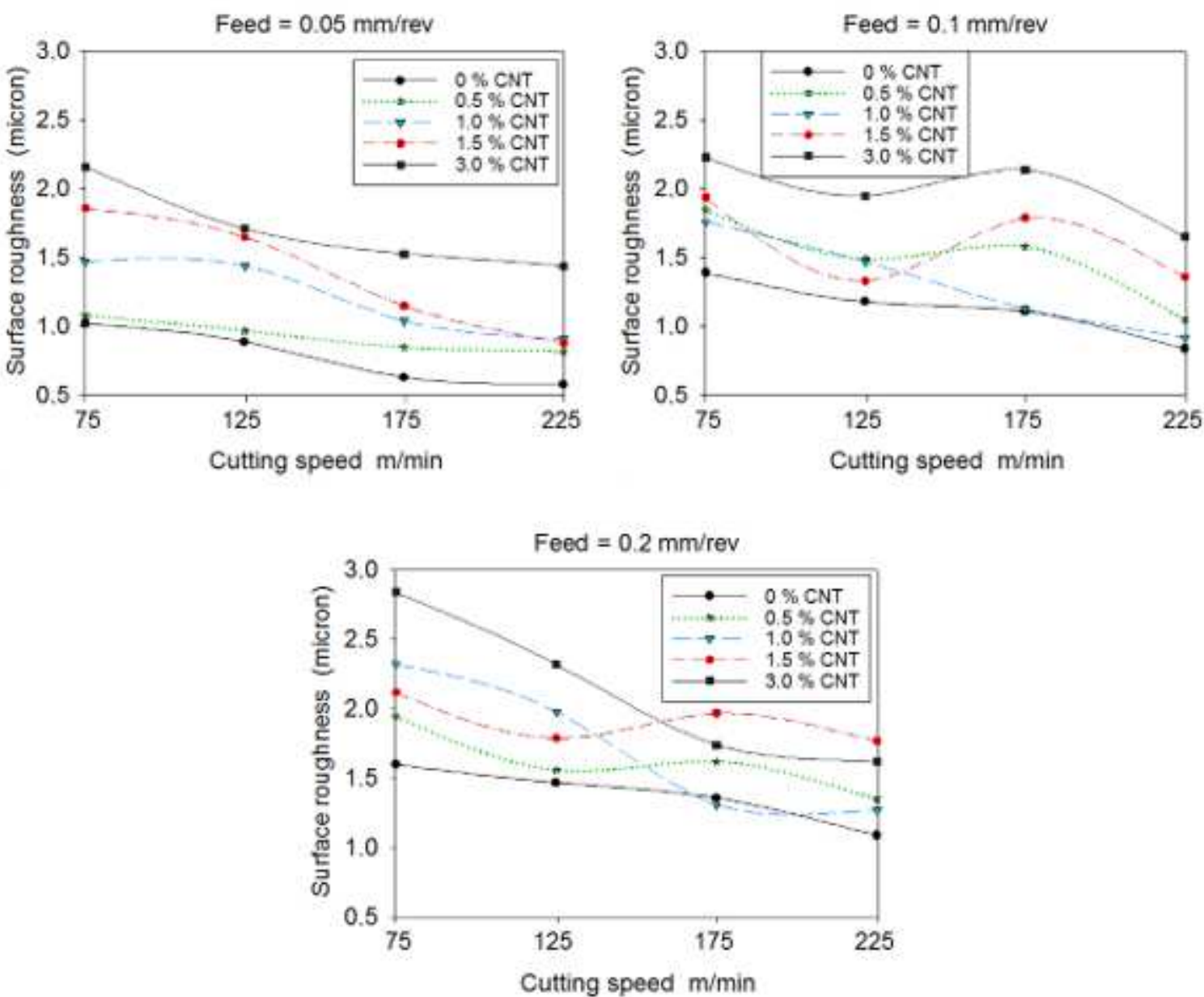

Figure 12

Surface roughness amounts according to feed in $0 \%, 0.5 \%, 1.0 \%, 1.5 \%$ and $3.0 \%$ CNT-reinforced ZA-27 composites

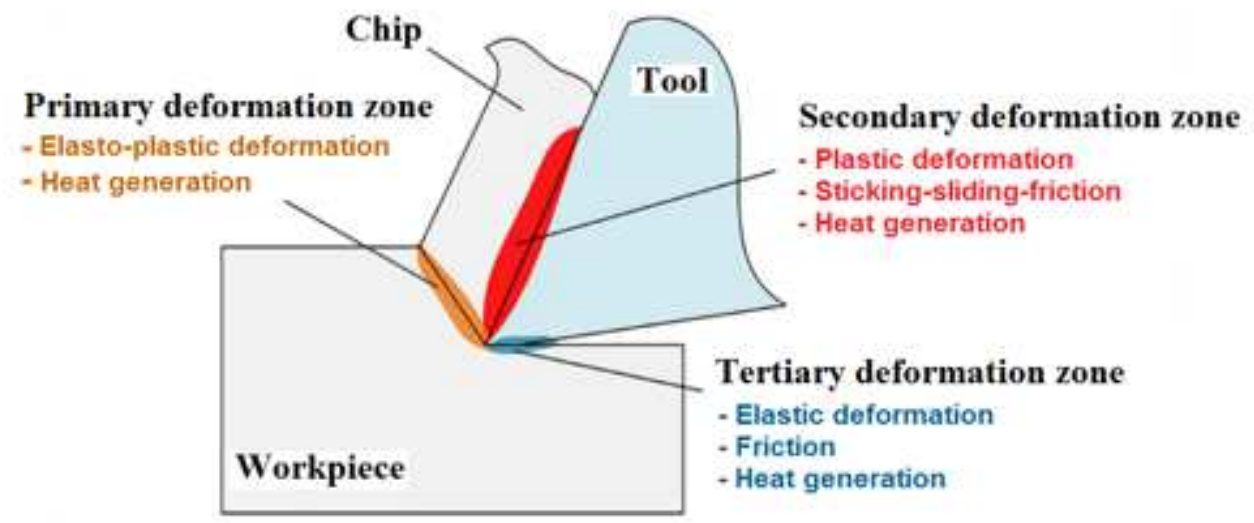

Figure 13

Sources of heat generation in the orthogonal cutting process [29] 

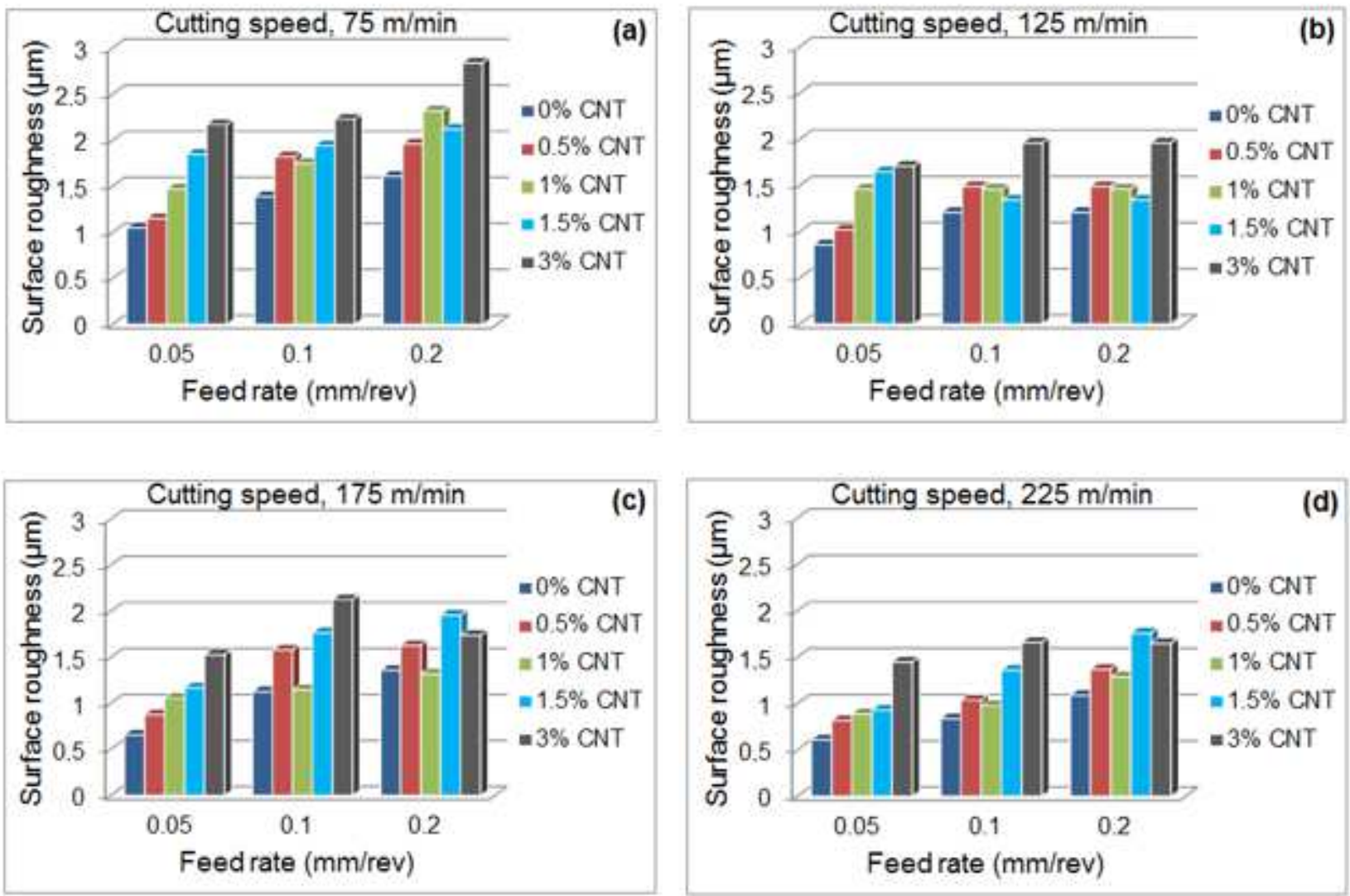

\section{Figure 14}

Surface roughness amounts according to the cutting speed in $0 \%, 0.5 \%, 1.0 \%, 1.5 \%$ and $3.0 \%$ CNTreinforced ZA-27 composites

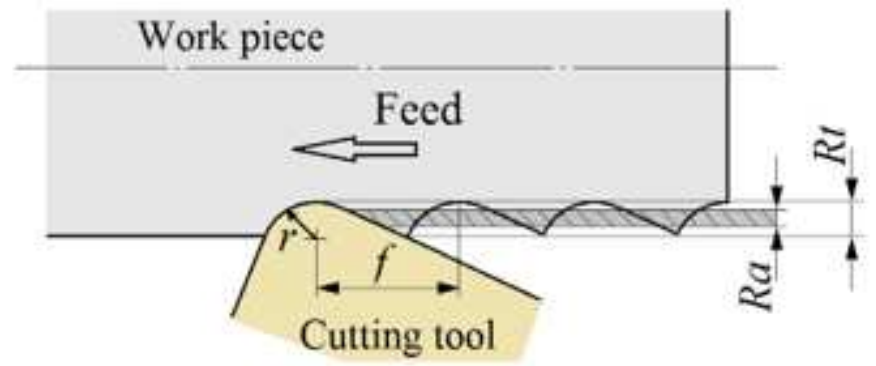

Figure 15

Surface roughness relationship with tool nose radius in machining 